\title{
Industrial Advanced Turbine Systems: Development and Demonstration
}

\author{
Annual Report \\ September 14, 1994 - September 30, 1996 \\ RECEVED \\ NOV 1 \& 1999 \\ OSTI
}

Work Performed Under Contract No.: DE-FC21-95MC31173

For

U.S. Department of Energy

Office of Fossil Energy

Morgantown Energy Technology Center

P.O. Box 880

Morgantown, West Virginia 26507-0880

\section{By}

Solar Turbines Incorporated 2200 Pacific Highway

San Diego, California 92186

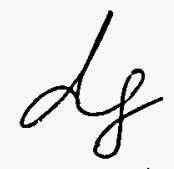




\section{Disclaimer}

This report was prepared as an account of work sponsored by an agency of the United States Government. Neither the United States Government nor any agency thereof, nor any of their employees, makes any warranty, express or implied, or assumes any legal liability or responsibility for the accuracy, completeness, or usefulness of any information, apparatus, product, or process disclosed, or represents that its use would not infringe privately owned rights. Reference herein to any specific commercial product, process, or service by trade name, trademark, manufacturer, or otherwise does not necessarily constitute or imply its endorsement, recommendation, or favoring by the United States Government or any agency thereof. The views and opinions of authors expressed herein do not necessarily state or reflect those of the United States Government or any agency thereof. 


\section{DISCLAIMER}

Portions of this document may be illegible electronic image products. Images are produced from the best available original document. 


\subsection{INTRODUCTION}

The U.S. Department of Energy (DOE) has initiated a program for advanced turbine systems (ATS) that will serve industrial power generation markets. The objective of the cooperative agreements granted under the program is to join the DOE with industry in research and development that will lead to commercial offerings in the private sector. The ATS will provide ultra-high efficiency, environmental superiority, and cost competitiveness. The ATS will foster (1) early market penetration that enhances the global competitiveness of U.S. industry, (2) public health benefits resulting from reduced exhaust gas emissions of target pollutants, (3) reduced cost of power used in the energy-intensive industrial marketplace and (4) the retention and expansion of the skilled U.S. technology base required for the design, development and maintenance of state-of-the-art advanced turbine products.

The Industrial ATS Development and Demonstration program is a multi-phased effort. Solar Turbines Incorporated (Solar) has participated in Phases 1 and 2 of the program. On September 14, 1995 Solar was awarded a Cooperative Agreement for Phases 3 and 4 of the program (DE-FC21$95 \mathrm{MC} 31173$ ) by the DOE's Office of Energy Efficiency and Renewable Energy (EE). Technical administration of the Cooperative Agreement will be provided from EE's Chicago Operations Office. Contract administration of the Cooperative Agreement will be provided from DOE's Office of Fossil Energy, Morgantown Energy Technology Center (METC).

Phase 3 of the work is separated into two subphases: Phase 3A entails Component Design and Development; Phase 3B will involve Integrated Subsystem Testing. Phase 4 will cover Host Site Testing.

\section{Program Manager's Assessment}

Complete program management data is being supplied concurrently with this report in Timeline format per the requirements of the Cooperative Agreement. A printout of the milstone schedule is also attached to this report.

Estimate at Completion: Forecasts call for completion of the program within budget as originally estimated. Scheduled completion is forecasted to be approximately 2 years late to original plan (September 2002 vs. September 2000). This additional 1 year delay has been intentionally planned in order to better match program tasks to the anticipated availability of funds. To ensure the timely realization of DOE/Solar program goals, the development schedule for the smaller system (ATS-S) has been maintained and is scheduled for completion in September of 2000 per the original plan. The development schedule for the large system (ATS-L) has been correspondingly delayed to accommodate the funding shortfall without undue impact to near-term program goals.

Overall Assessment of Performance: ATS engine development activities continue to progress well. Work is $8 \%$ complete based upon milestones completed. Significant milestonies over the past year have included the formal completion of concept development activities as marked by the successful Preliminary Design Review (PDR) held at Solar Turbines on 1 April 1996. Concept revisions to address improvements identified during the PDR have also been completed, paving the way for formal initiation of the detail design phase of the program on 8 April 1996. Technical development activities required in support of key technical challenges identified during concept 
definition activities are proceeding on track, with no known roadblocks identified. Backup development activities, defined to augment those technical challenges identified as medium or high risk, are continuing in parallel per the original program plan. Detailed design activities for the shaft and bearings have fallen behind plan and are being addressed with additional management supervision. No negative impact to the overall program schedule or budget is anticipated from this near-term slippage.

Commercialization efforts, one of the key items to the overall success of the ATS program, are performing extremely well per plan. Specifically, design-to-cost activities have resulted in a baseline product design with a cost estimate that is currently $10 \%$ below the target necessary to achieve the stated DOE/Solar program goals. Development of Solar's formal commercialization plan detailing the required efforts to promote distributed generation, appropriately shape the ATS product and communicate the applicability of ATS products to fit these needs is on track for completion in March 1997 per plan.

\subsection{TECHNICAL PROGRESS SUMMARY}

The last twelve months has seen the transition from a rough engine concept to a full-fledged workable engine design during which time numerous design challenges have been encountered and to a large degree, resolved. The new engine is so different from any other engine that Solar has in its product portfolio, that design solutions have come under significantly more scrutiny than is usually the case from the Solar Engineering community. As a result, progress has been somewhat slower than anticipated, but the quality of the final product will clearly benefit from this additional investigational effort.

It is noteworthy that the new engine concept originated from a completely clean sheet design, without resorting to any scaled hardware from any other Solar product, except for few instances of turbine disc forging dies and compressor/turbine blade attachment schemes where manufacturing costs can be minimized by using existing tooling. This means that $99 \%$ of the engine will be designed "from scratch", without the benefit of previous (similar or scaled) work with which to compare.

The engine design has been progressing steadily, with a small number of very key considerations having a significant influence in design decision making. These are:

i) engine life-cycle cost and first cost

ii) modularity/maintainability

iii) efficiency

Many changes in the design have occurred over the last year due to the above considerations. For example, the engine must meet aggressive cost targets which have resulted in material choices requiring thorough mechanical and thermal analysis in order to achieve life goals. From an overhaul perspective, the engine has been configured in a "modular" arrangement whereby each module can be removed for field replacement or shipment back to an overhaul facility. This will have a major beneficial effet on maintainability of the system. Aggressive engine efficiency targets have been achieved through the introduction of a number of advanced technology items including new hot section material development, advanced aerodynamic airfoil designs and rolling element (low friction) bearings. 
Given that this is a clean sheet design, a concerted attempt has been made to involve all functional areas, including suppliers, from an early stage in the design process. Concurrent engineering has been practiced on this program as an integral part of Solar's "new product introduction" (NPI) process. This process has proved very effective in coordinating the design to achieve a fully optimized product from the customer prospective.

The detail engine design has much more work to be completed, with many challenges to overcome, but engineering drawings are beginning to be released. This release activity will increase significantly over the next few months. Major issues currently being addressed are turbine tip clearance control, combustor liner temperature control and thrust balance management. There are, however, no challenges foreseen which could force a significant deviation in engine concept.

\subsection{TECHNICAL PROGRESS BY TASK}

\subsection{S Engine and Package}

\section{WBS 10200 - Engine Definition}

A significant effort was spent over the first several months of the contract in refining the concept for the S-engine. During this period, engine cycle studies played a major role in determining the progress of the engine layout. Each contributor to overall thermal efficiency was examined in detail so that the sensitivity and relationship of each aerothermal and mechanical design parameter to the efficiency goal was fully understood. Substantial input regarding the concept was obtained from DOE at the first quarterly review, held on February 7-8, 1996. Although the concept refinement has impacted the front end of the program schedule, the delay should be recoverable.

A Preliminary Design Review was held on April 1, which highlighted concerns regarding the shaft dynamics, combustor size and cost and overall package dimensions. Modifications were made to the configuration to address these issues, and detail design commenced in earnest. The Product Requirement Specification for the $S$ was released in late April.

This task is deemed complete although fine tuning of the cycle will continue as detail design proceeds. Engine performance numbers are updated in an iterative fashion since efficiency (and power) variations at the component level are important in establishing the validity of the overall engine design. The most recent analyses indicate engine efficiency at the shaft of $42 \%$ and busbar efficiency of $40 \%$.

\section{WBS 10300 - Package Definition}

The packaging group has focused on developing the design concurrently with the $S$ engine design team, recuperator design team, marketing, and the ATS program office to develop the engine design and integrate it into a packaged system. Most of the effort has focused on a general package layout concept. Solar's packaging philosophy is to create a flexible design that will accommodate the standard options that we believe the customer will want to purchase. To that end, a preliminary Application Check sheet (ACS) has been created. This document identifies the standard package options available such as a selection of generator voltages, fuel system configuration(gas or dual fuel), inlet and exhaust filter and silencer selections, and whether or not the unit will be enclosed. 


\section{WBS 11100 - Air Inlet System}

Various air inlet configurations were studied in order to ensure maximum uniformity of flow into the air inlet. Initial analyses suggested that the duct would need to come in from the side of the engine to minimize flow distortion. However, additional investigation including further CFD work has shown promise that a vertical air inlet system feeding air to the compressor from above the engine is possible without significant adverse effects on the aerodynamic performance of the inlet. CFD work is in progress to minimize the losses through a vertical air inlet duct. This duct will have to be split to provide access to the center of the engine.

Three CFD models of the ATS-S engine inlet were created during the past quarter. These models included an isolated inlet/engine muff configuration, a straight duct connected to the engine muff flange (the baseline configuration), and a duct with 2 mitered 60 degree bends which represented a configuration for a top mounted inlet. Although this last configuration would not fit on the engine package configured at that time, it was considered a first iteration of a functional inlet. Results from these models were reviewed and the conclusion was made that the top mounted inlet showed less pressure and velocity distortion than had been anticipated. With the reduction of the leading edge radius of the cast inlet struts, greater flexibility now exists to sculpt the ducting to bring the pressure and distortion levels within acceptable limits. A new model is currently being created.

A preliminary ANSYS stress model was also generated to analyze the assembly load effects on the air inlet housing, and perform stress sensitivity studies based on the inlet strut configuration. Initial results have shown that the strut stresses have acceptable margin, and the struts were then reduced in diameter. Stresses for this new configuration were also acceptable, and as a result provides more flexibility for the design of an acceptable vertical inlet duct.

\section{WBS 11200 - Compressor Assembly}

The flow path definition for the compressor was essentially completed in the first quarter of 1996 with a design review held in March.

Since all of the blades, attachments, and stators of the $S$ engine compressor are unique, the design of the various components has been undertaken more or less in series. Aerodynamic work on all static and rotating airfoils is approximately $50 \%$ complete. Mechanical analysis of the airfoils and disks is well underway. 2-D and 3-D finite element models have been developed to estimate compressor blade and vane stresses, frequencies, mode shapes, and displacements during nominal operating conditions.

Rotor balance has received a significant amount of attention during the compressor design phase as has the design of the bearing system. Numerous rotor configurations were considered during early design stages. Since Solar Turbines has relatively limited experience with rolling element bearing design for high-speed, mainshaft bearings, external assistance has been extensively used in the preliminary design of the bearing system.

Greater detail regarding the activities undertaken over the past quarter is provided below.

Compressor Case: The compressor case material has been the subject of much investigation over 
the last quarter. Two materials have been considered as potential candidates: ductile iron and 410 stainless. Selection issues involve the compressor blade tip clearances relative to the growth behavior of the materials. As a result, the thermal growth characteristics of the compressor case has been under investigation.

The S-engine is being designed with a split case similar to Solar's Centaur 50 and Taurus 60. (The main reason for the split case is to allow the rotor to stay assembled after it has been balanced). Because the S-engine will be similar in size and have similar airflow characteristics, it can be assumed that the time taken for the S-engine case to heat up will be about the same as the Centaur 50 (approximately 17.5 minutes). Rotor temperatures were taken on the Taurus 60 compressor test rig with slip rings. Since the rotors are very similar between the S-engine, the Centaur 40 , and Taurus 60 , the S-engine rotor should reach steady state temperature in about the same time (approximately eight minutes). Tip clearance has been calculated based on this assumption.

At start-up, the clearance is reduced by approximately .007 inches due mainly to CF growth and thermal growth of the blade. The clearance is reduced further by the thermal growth of the rotor. Finally, the clearance increases due to the slower thermal growth of the case. The case material has a significant influence on the final running clearance since it is the last step in the growth sequence. Using a material with a low thermal expansion for the case would help minimize the running tip clearance. However, since the temperatures are relatively low (about $600^{\circ} \mathrm{F}$ ), the improvement is very small. If the disk material were changed, the resulting running clearance would be about the same because the case is the controlling feature. The cold clearance would have to be increased to maintain the minimum clearance but the final running clearance is still dictated by the case growth.

Since cost is a major factor in the S-engine design and there appears to be minimal improvement by using 410 stainless as described above, it has been decided to make the case material out of sand cast ductile iron. The disk material will be forged 410 since there is no improvement in tip clearance by using AISI 4340.

The ACE compressor test rig is.scheduled to run the first quarter of 1997 under WBS 42100 . This compressor has a 410 split case, and a rotor which is similar to the S-engine. It will be instrumented with a "rota-data" tip clearance probe system. The results of this test will be applied to clearances calculations for the S-engine. The final clearances will be dictated by the S-engine tests where the running clearance will be optimized.

Variable Vane System: The variable vane actuating system has been reviewed to determine the mounting requirements and how they affect the compressor case. The Taurus 70 system appears to be the simplest and probably the least expensive system. The rotating shaft with arms of various lengths provides more flexibility in selecting vane travel. An electric actuator will drive the vanes. The current Taurus system is being revised to simplify the hardware and add an electric actuator. These improvements will be incorporated into the final design for the S-engine. The guide vane bushings and arms will be the same size as the Mars engine. This size simplifies machining. The Taurus 70 rollers and axle design will be used to support the split unison rings on the compressor case.

The effort to incorporate a cantilevered design for the 1st and 2 nd stage variable guide vanes or stators has been successful. This would reduce the number of parts and therefore reduce the cost of the compressor assembly. Also a button and shaft design from the Mars engine was used for both 
the 1 st and 2 nd stage vanes. This cantilevered design plus the use of existing hardware will reduce the number of parts and cost to the compressor assembly. All of the stators have been carefully evaluated for $\mathrm{HCF}$ tolerance, and no problems are expected during normal engine operation.

Seal System: The seal system on the S-engine has been fine-tuned over the last few months in order to obtain an optimized thrust balance configuration for the rotor system. An integral part of this system is the aft compressor hub seal. The seal diameter on the aft compressor hub has been minimized to help minimize the thrust load on the engine. Using a step seal with as small a diameter as possible will create the largest cavity and therefore the highest load to offset the turbine thrust. The smaller seal diameter will also make the seal more effective and require less air flow. The air that flows through this seal can then be used to buffer the inlet bearing seal and the turbine bearing seal.

Preliminary analysis of the engine axial thermal growth has shown undesirable spacing between the aft end of the compressor rotor and the exit guide vane. The major cause of this growth is the high temperature and high thermal expansion material in the turbine section. The gap also increases by the amount required to assemble the rotors after bolting the compressor and turbine housings together. Because this gap must be reduced, the center section and turbine area are being reviewed for a redesign. Mating the curvic coupling teeth on the shaft at the same time that the housings come together is also under consideration. This will require an alignment tool designed to prevent curvic tooth damage at assembly.

Compressor Diffuser/Collector: During the last quarter, five axisymmetric CFD models of the compressor diffuser were created representing three diffuser angles and diffuser lengths. The results of these models led to the creation of three other models to investigate the effects of the collector flow area on the diffused flow. These results were incorporated in the construction of a full 3dimensional model of the diffuser/collector system. A converged solution from this model has not yet been obtained.

Also, a preliminary ANSYS finite element model was generated to investigate the diffuser stresses as a function of pressure loads. The analysis was driven by the unique geometry of the diffuser, with respect to other Solar designs, and the material choice of ductile iron. The analysis showed no major issues with the material choice. A refined model with a modified outlet scroll will be analyzed as soon as the aero definition is complete. This model will incorporate both pressure and assembly loads.

CFD analysis for the proposed compressor diffuser shows a length of the diffuser that would make an integral casting difficult to cast. As a result alternatives are currently being reviewed to separate the diffuser wall from the main case.

Compressor Rotor: During the last quarter, 2-D and 3-D finite element methods were extensively utilized to calculate the compressor component stresses, frequencies, mode shapes, and displacements during steady state and transient operations.

The design of the first 4 stages of compressor blades and stators has been completed. Use of existing designs and hardware will be made where appropriate to reduce time and cost in producing the compressor. The airfoil and dovetail attachment definitions for the blades have been released for incorporation into the compressor layout. 
An analysis of the first four stages of compressor rotor disks and spacers has been initiated. All stages of disks will be connected through curvic couplings. With the exception of the 1st stage curvic, all curvics will be made from existing designs. The long chord lengths in the new airfoil designs have made the 1st and 2nd stage spacers longer than those which are currently used in Solar production engines. Various design configurations and material selections are being evaluated to select a spacer design that will be stiff, strong, and lightweight. These three qualities are desired to minimize the radial deflection into the flowpath and reduce the load on the adjacent rotor disks.

A 2-D finite element model of the entire rotor assembly is being systematically updated with final details as the disk and blade designs are being finalized. The rotor model will be used for transient and steady state heat transfer analyses in addition to the design of the compressor tiebolt.

\section{WBS 11300 - Combustor System}

The emphasis during the early part of the year focused upon an analysis of various combustor configurations for the ultra-lean premix system including axial annular, canted annular, multi-can and canted two-can approaches. These configurations were compared with regard to achievable emissions levels, cost, ability to accomodate a later catalytic combustion system, accessibility and maintainability. The selection of the basic configuration was made in the first quarter of 1996.

Combustion tests were conducted to examine the emission performance potential of the ULP combustor operating at the high combustor inlet temperatures that will be present under $\mathrm{S}$ engine conditions. These high inlet temperatures provide an opportunity to achieve lower NOx emissions by operating at reduced flame temperatures. CFD analysis of the system has demonstrated the need for variable geometry to control the combustor flame temperature in order to meet emission goals over the 50 to $100 \%$ load range. Thus various alternative approaches to variable geometry injectors have been examined, and detail design proceeded carrying two alternatives in parallel pending the completion of sufficient analysis to make a downselection.

Significant attention has also been given to the geometry of the combustor housing. An attempt was made to design a "universal housing," or a housing that could be adapted to both the ULP and catalytic can configurations. However, since future catalytic configurations (and design criteria) are likely to change dramatically in the next few years, the design team decided not to compromise the ULP housing desing by incorporating current catalytic dimensions. However, the design has proceeded in a manner that continues to acknowledge the retrofit requirement and the relatively larger catalytic surface areas and volumes.

Greater detail regarding the activities undertaken over the past quarter is provided below.

Variable Geometry Concept Selection: Two combustor variable geometry concepts were worked in parallel during the last quarter. One concept, the internal valve variable geometry (IVVG), consists of a large valve in the combustor inlet pipe for injector flow modulation, a divider plate separating the flow between the injectors and liner, and a housing whose larger size acts as a manifold and allows airflow to distribute effectively. The other concept, the external valve variable geometry (EVVG), consists of a separate downcomer from the recuperator that contains a valve for injector flow modulation, an external manifold for this flow, a slightly smaller combustor inlet pipe (like the IVVG), and a smaller combustor housing (which is possible since the injector airflow is 
distributed externally).

The IVVG concept was ultimately selected due to several factors:

i) The EVVG concept required flex hose to connect the external manifold to the injectors. The flex hose life at $1170^{\circ} \mathrm{F}$ is unpredictable.

ii) The cost of the flex hose and clamps is estimated at more than $\$ 25,000$ - more than the cost of the extra material needed for the IVVG housing.

iii) The higher weight of the IVVG housing is balanced by the additional weight of the externals on the EVVG.

iv) The IVVG concept has superior injector aerodynamics and ability to modulate flow more accurately.

Combustor Casing: A significant amount of effort was directed at the combustor case design and minimizing the cost of this complex casing. Initially, Inconel 718 was chosen for the combustor casing due to its superior tensile and creep strength. However, intensive investigation regarding fabrication of this part led to elimination of the material from consideration because of excessive cost. During this investigation, two fabrication options were studied: rolling and welding large rings, or flash welding rings. Estimates for the cost of such rings were well in excess of plan. AISI 347 steel has been selected as a possible alternate material.

A 3-D finite element model was constructed and preliminary stress rupture lives calculated at different housing locations (different stresses and temperatures) for the 347 material. This material is very sensitive to temperature and stress levels at S-engine running conditions, and initial calculations have shown that an AISI 347 combustor housing may be an engine life limiting component. As a result, design effort will be directed at reducing the general level of stress in the part, along with design modifications to reduce the severity of regions of stress concentration.

The results of the 3-D finite element model reveal stress concentrations around the inlet pipe hole, injector holes, and other housing discontinuities. These results will be used to help with further design iterations. Reinforcement will be needed around the inlet duct, and the endcover has been domed inward to eliminate the discontinuities that existed in the stepped endcover (i.e., the step locations). Also, a ring of material was added to the dome at the injector location for injector fastener thread engagement. This material also reinforces the injector holes. Preliminary heat transfer calculations have been made in order to estimate metal temperatures around the housing and endcover. These metal temperatures are important since the working conditions of the 347 alloy are at the upper end of its temperature/strength capabilities.

\section{WBS 11400 - Recuperator Section}

Recuperator Design: The S-engine air cell design has been finalized. This design is based on the Solar hi-capacity air-cell that was commercialized for Frame-3 retrofit applications but it differs by having a longer counterflow heat-exchange path. The longer counterflow path increases the effectiveness as well as the pressure drop of the recuperator. Increasing the " $\mathrm{X}$-dimension" has 
important ramifications on size and cost. First, a greater percentage of the foil is used for heat transfer surface. This results in higher compactness for the core although it is taller. Hence it costs less and is somewhat smaller in overall size.

The interface of the recuperator with the engine and package has also been finalized. A principal design issue was bowing of the recuperator because of the inherent thermal gradients. The highest temperatures occur at the bottom of the recuperator where the hot turbine exhaust gas enters, and the hot, recuperated air exits to the combustion system. It is much cooler at the top of the recuperator where the compressor discharge air enters the recuperator and the exhaust gas, now much cooler, exits. The interface design is grounded on taking the weight of the recuperator through the air out pipe and down through the combustor case. The air ducting system is comprised of two air inlet pipes and one air outlet pipe. Each air inlet pipe contains two gimbals and one standard bellows to provide the movement necessary in all three planes. The air outlet pipe contains a single bellows and the gas inlet ducting contains a single rag-type expansion joint.

Performance Prediction Model: A 3-dimensional analytical model was developed to improve performance prediction capabilities. The baseline performance of the S-engine recuperator was established using an in-house recuperator performance model. This model estimates the thermal effectiveness and pressure drops on both the air and gas sides of the recuperator. However, this model does not take into account the distribution of air into and out of the air cells through the conical headers.

The cylindrical headers through which air enters and leaves the recuperator core influence the envelope geometry and configuration of the recuperator. They can also affect the air flow distribution in the recuperator air cells while simultaneously impacting thermal effectiveness of the recuperator and its air-side pressure drop. In general, the air pressure levels inside the inlet and outlet cylindrical headers vary depending on the type of cycle selected and the cycle pressure ratio. With applications such as the ATS S-engine, where the High-Capacity air cells are used, the headers can be quite large. Due to high air pressure inside, the cylindrical headers are generally thick, making them a heavy and expensive part of the recuperator system. The 3-D model includes detailed aerothermal representations of the counterflow core, air- and gas-side triangular headers, and the air-side inlet and outlet cylindrical headers, which enables one to find the pressure, temperature, and flow distribution along the length (cell-wise), width (span-wise), and the counterflow length of the recuperator. The 3-D model also enables analysis of potential header alternatives in order to optimize performance of the recuperator and to minimize the cost. This model will be used during the final design of the S-engine to optimize the conical headers for uniform flow distribution in the core, thereby maximizing the performance of the recuperator.

Two methodologies were developed for the analysis of the S-engine cylindrical headers. The first methodology addresses the aerothermal analysis of a given header design, aimed primarily at establishing the cell-wise flow distribution in the recuperator core and its implications on the recuperator performance. The second methodology was aimed at synthesizing an optimum header design to yield a uniform cell-wise flow distribution in the recuperator. The former methodology is part of the 3-D model of the recuperator and establishes the flow rate, pressure, and temperature distribution in the entire recuperator, including the inlet and outlet cylindrical headers, inlet and outlet triangular headers and the cell-wise flow distribution in the recuperator core. The effects of the header geometry and configuration on the overall performance of the recuperator was also established. 
PSR Cell Wave Form Analysis: An analysis was performed to investigate the effects of using a different wave form shape on primary surface recuperator foil material. The PSR wave form is made up of circular arcs connected together by straight lines. These straight lines form flat sections in the folded profile which produce high bending stresses. Because creep is a function of stress, it is desirable to reduce the stress in this area which will result in less creep or bulging. A modified wave form that eliminates the flat section and reduces stress was developed. The wave form is made up of slightly larger radius arcs connected to each other at inflection points. Stress analysis was performed on both wave form shapes using ANSYS. Finite element models using 3-D elastic shell elements (SHELL63) were created for the current and new wave forms.

Two different analyses were performed for each wave form. The first analysis examined the difference in foil thickness between the two wave forms for each to produce approximately the same maximum stress. The current geometry and pressure of the ATS S recuperator was used as a baseline for this model. The modified wave form with a thickness reduced by $9 \%$ is predicted to yield a creep life similar to that of the current wave form. The second analysis examined the additional creep life that the modified wave form produces over the current wave form for the same conditions and foil thickness. A Larson-Miller curve was used to determine the life for $5 \%$ creep of 347 SS foil for each wave form. A $325 \%$ increase in predicted life was achieved by using the modified wave form.

Recuperator Manufacturing is not able to determine at this time if the folding blades and folding process may be modified in order to change the current folded profile to the new modified profile. Because of the geometry and physics involved, reduction of flats within the profile geometry will require a series of trials of various blade geometries in order to determine the amount of change in profile possible. There is no plan to further pursue this investigation at this time due to higher priorities given funding limitations.

Liquid Fuel Study: A rig test was designed to test a recuperator core under typical ATS conditions using a low $\mathrm{NOx}$, low smoke combustion system operating with diesel fuel \#2. The small passages of the primary surface recuperator could be problematic if the exhaust is not clean. The fouling core test was finished during the summer of 1996 after the core had been exposed for 1000-hours. The increase in gas-side pressure drop was minor indicating that sustained liquid fueled operation is practical.

Creep Core Test: A creep core test was conducted to better understand creep of the primary surface folded profile since creep is expected to be the dominant potential failure mode. Small recuperator cores or "creep cores" were designed and built and placed in a furnace. A core of stainless 347 and one of Inconel 625 were tested, each for a period of 90 days. They were exposed to a thermal environment of $1300^{\circ} \mathrm{F}$ so that the expected $5 \%$ creep would occur within the three month test period. The air side of each core was pressurized with nitrogen rather than air so that oxidation would not be contributing. The cores were placed in individual retorts which were kept under a slight purge of nitrogen. The cores have been photographed and visually inspected. There was visual evidence of some creep in the expected high-stress areas of the core, which was consistent with a finite element model prediction. The cores will be sectioned and measured to estimate the degree of creep which should provide some validation for the creep prediction methods currently in use. 
PSR Material Creep Analysis: In order to more accurately predict the creep life of a primary surface recuperator core, ANSYS finite element analysis has been used to determine the creep deformation of folded foil during operating conditions. A 2-D model of two cells, four folds wide, with a .003 " foil thickness was run for $5 \%$ creep. The model allows computation of the deformed area of the gas passage after the model has been run.

Results of the ANSYS model were compared to the creep testing done on Type 347 SS core specimens. The creep core test specimens were $.0045^{\prime \prime}$ foil thickness and were tested up to $5 \%$ creep. The test specimens were cut up, photographed, and scanned into CADDS5 for analysis. A comparison was made between the ANSYS model and the test specimen of the change in area of the gas passage for $5 \%$ creep. The difference between ANSYS prediction and the test results was $21.6 \%$. The ANSYS model will require further development to more accurately predict the creep deformation. This will include the following: 1) use of a different material constitutive model to predict plastic deformation through the use of a user subroutine; 2) use of a different finite element software package with more robust nonlinear capabilities; 3) determination of the residual stresses from the foil folding process and their inclusion in the finite element model.

Flattened Tube Test: A flattened tube test was also conducted to attempt to predict creep behavior of the PSR folded fin. The flattened tube has been shown to produce a stress distribution similar to that of the PSR folded fin under pressure. The flattened tube specimens are the same size as a 20/1 scale PSR folded fin. A 2-D ANSYS half model of the tube using PLANE42 elements was used to predict creep.

High temperature creep testing was conducted on 347 SS and Haynes 230 flattened tube specimens. Dimensions were taken at approximately the quarter and half span locations of each specimen at the beginning of each test and at various intervals throughout the testing. The results show that the ANSYS model underpredicts the creep deformations by approximately $30 \%$.

Two discrepancies between the testing and analysis are likely to cause the analysis to underpredict the creep deformation. First, the creep equation used in the analysis was a secondary creep equation, and primary creep was neglected. This implies that the creep strain rate was assumed to be constant over the entire period of time. However, the strain rate during primary creep is greater than that of secondary creep. Thus neglecting the primary creep would result in a decrease in overall creep strain. Secondly, residual stresses in the tube resulting from the flattening of the tube were not taken into account. Refinement of the model is necessary to account for primary creep as well as the forming process of the tube.

\section{WBS 11500 - Fuel System}

With the basic definition of the combustor design having been completed in mid-1996, detailed investigation into the fuel injectors has proceded. A principal issue has been the selection of the variable geometry method most appropriate in light of performance, reliability, maintainability and cost goals. (See discussion under WBS 11300.)

Testing on an existing single injector combustion rig was conducted in order to provide guidance on the combustor volume required to achieve emissions goals. Early testing was conducted with conventional film cooling requiring flame quenching; hence volumes determined from that testing were conservative. 
Significant progress has been made on the S-engine fuel system over the past quarter. Highlights for this period include:

- The internal valve variable geometry (IVVG) has been selected for the combustor design.

- Initial Computer Fluid Dynamics (CFD) studies have been completed of the aerodynamics of the inlet flow to the injectors.

- The design operating flame temperature has been selected based on combustion tests.

- A heat transfer analysis, supported by combustion tests, has been undertaken to determine the enhancement factor goal for the "backside" cooling scheme.

- The three full load operating conditions of peaking, intermediate and continuous duty have been examined in terms of emission control and liner wall cooling air flow.

- The basics of the control methodology for the variable geometry system have been defined.

These are discussed in further detail below.

Initial CFD studies have been completed on the inlet air feed to the injector plenum on the Internal Valve Variable (IVVG) system selected for the S-engine combustor (see WBS 11300 discussion). The results were encouraging in that they indicated that it should be possible to hold the individual injector air flows to within a range which is acceptable for flame temperature control, with a circular grid plate operating with the target parasitic pressure loss.

Combustion tests were conducted on the experimental low emission gas injector backside cooled liner combustor system. These tests showed that the combustion flame temperature would have to be limited to $2675^{\circ} \mathrm{F}$ if $10 \mathrm{ppm}$ NOx were to be achieved on the S engine - as compared to the $2850^{\circ} \mathrm{F}$ initially taken as the design point. The lower temperature has now been adopted, which introduces some conservatism into the design. It is hoped that improvements can be made to the premix efficiency of the injector to allow for higher temperatures without jeopardizing the emissions target.

Further combustion tests using the same experimental hardware with thermocouples attached to the liner wall, have shown that the heat flux to the liner wall is consistent with the values calculated in an theoretical analysis of the liner wall heat transfer conditions. This indicates that the assumptions used in the analysis with regard to the flame emissivity and the gas side wall convective heat transfer coefficient are valid. The analysis also suggests that thermal barrier coatings will be needed to reduce the heat flux to the wall in order to reduce the required enhancement factor. More analysis and testing is planned to refine these findings.

An initial analysis has been performed on the combustor operating conditions associated with the peaking duty engine conditions. At the peaking conditions the combustor air inlet and gas outlet temperatures are higher than the basic intermediate duty design point. To achieve the required emission levels at the peaking duty requires increasing the air flow through the injectors, reducing the air flow available for cooling and increasing the liner wall temperatures.

The basic form of the control algorithms have been defined for modulation of the diverter valve assist in the establishment of a control specification for the engine. The valve will be both open loop and closed loop controlled. Open loop will be used to allow the fastest possible response to a change 
in engine load. Closed loop, using a $\mathrm{CO}$ sensor in the engine exhaust, will be used to achieve the final trim to the required emission levels.

\section{WBS 11600 - Turbine System}

Numerous cycle studies were performed over the first several months of the cooperative agreement to optimize overall cycle efficiency and cost. Parametric studies were performed to optimize the hub diameter for given cooling regimes. The turbine flowpath was fixed, with streamline definition provided to the mechanical design and heat transfer groups. Detailed design of the turbine components began in April.

The cooling arrangement for the S-engine is challenging due to the relatively high temperature of the cooling air coming from the recuperator. Only a small portion of the cooling flow is compressor discharge. A significant reduction in cooling flows has been achieved through a combination of improved materials, coating and service life strategy. Several of the technology development programs reported under WBS 19000 , et. seq., will provide information and test verification regarding technologies that will help overcome these challenges.

A preliminary analysis of the aft bearing cavity in early 1996 indicated that a post lube cycle might be necessary. A transient thermal model was therefore undertaken to understand the transient effects on shutdown and the beneficial impact of various cooling options, in order to minimize the post lube cycle. A steady state turbine rotor finite element analysis for the design point condition was completed in order to determine metal temperatures of the thrust bearing cavity, and sensitivity analyses have characterized the effects of varying buffer air temperatures as well as the effects of under-race lubricant heat transfer coefficients on overall shaft temperatures. During the second quarter seal design concepts were specified and included in the thermal analyses.

Preliminary designs of the bearing stub shaft and of the interface of the bearing housing and exit guide vane segments were completed during the first quarter of 1996.

A primary area of focus throughout the year has been ensuring the modularity of the engine design in order to facilitate assembly and field service, with beneficial impacts on RAMD and cost.

Greater detail regarding the activities undertaken over the past quarter is provided below.

Stage 1 Nozzle: An analytical model of the first stage nozzle has been built, and the analysis is progressing well. The model defines the inner and outer location features and the plenums required for impingement cooling both end walls. The inner wall cooling utilizes a double plenum scheme, the external plenum capturing excess air from the leading edge cavity, while the inner skin contains the impingement cooling holes.

Heat transfer analysis has been performed for a number of scenarios, both with and without thermal barrier coatings (TBC). For equivalent cooling flows the TBC provides only $30^{\circ} \mathrm{F}$ enhancement. The reason for this small benefit can be attributed to the low heat flux due to film cooling and the elevated temperature of the primary cooling air. TBC's work best with high heat fluxes. Some benefit can be derived from the potential hot spot damping capability; however, this tends to be negated due to potential spallation occurring at the leading edge based on the experience of other 


\section{manufacturers.}

Preliminary stress analysis which takes into account gas loads and pressure loads from the diaphragm indicate low stresses.

Stage 1 Blade: Heat transfer analysis has been completed to establish a preliminary flow network analysis of the core. The indicated blade mid span temperature is below CMSX-4 material target temperatures to ensure life requirements, but does not give adequate margin for perceived uncertainty in the analysis.

Sufficient progress has been made on the first 3-D blade core to perform initial 2-D ANSYS thermal analysis. The core is being designed to accommodate CMSX-10 single crystal material. Using this design will result in the potential for higher firing temperatures for the peaking cycle or enhanced service life.

Disk and Rim Seals: The first stage disk forging is similar in shape to an existing production stage 1 disk. It is anticipated that use of the existing forging or at least the existing tooling for the first few sets of engines will be allowed. The preliminary stress analysis of the disk with the rim seals attached shows centerline stresses well within acceptable levels. The disk can be further optimized and still accommodate the required burst margin. Analysis of the rim seals show acceptable stresses and deflections.

Stage 2 Nozzle and Diaphragm: The stage 2 nozzle and diaphragm are being designed by a subcontracted engineering firm - Agilis Group, Inc.. Agilis has completed the preliminary design on the nozzle segment and diaphragm. The stresses in the initial iteration were low enough to permit a decrease of the interstage seal diameter and thus reduce thrust load on the rotor.

Maximum stress has been found at the corner fillet of left hand forward hook. The location is due in part to the positioning of the tangential load restraint. Calculated bulk stresses in the airfoil are acceptable for the design intent.

Stage 2 Blade: The second stage rotor involves a new shrouded blade design. The shrouded blade design is nearly complete, and the shroud itself has been balanced to the point where the majority of the bulk and concentrated stress levels are acceptable in Mar-M-247 Equiax material. Further modal analysis and thermal transient response is expected to uncover new peak stress locations and will require further evaluation.

The turbine disk has undergone a preliminary finite element analysis. The 3-D disk sector model has been compiled and run with centrifugal load at steady state bulk temperatures. The stress levels obtained agree very closely with the preliminary design calculations.

Material properties for U-720 intermediate grain size are currently being gathered through ATS development programs with various material suppliers. The basic design entails a disk of approximately $120 \mathrm{lbs}$., which meets all Solar criteria for post stresses in creep, bulk average tangential stress for overspeed protection, and concentrated stresses in bolt hole locations for low cycle fatigue. 
Nozzle Case: The S-engine nozzle case will be made of Haynes 242. This material does not have as low an expansion coefficient as the usual Incoloy 900 series, but strength requirements at S-engine temperatures are driving the material choice. The number of suppliers with experience in forging 242 is very limited; so a development plan has been evolved which emphasizes the early introduction of this material into the first test engines. Supplier selection is ongoing.

Cooling schemes are currently being developed to impingement cool the second stage nozzle forward hook region and reduce temperatures to acceptable levels. In concert with the reduction in temperature, the loads into the hook from the first stage nozzle and the second stage nozzle are being configured to counterbalance one another to minimize the bending moment.

Exhaust Collector and Diffuser System: The initial S-engine design used a structural exhaust diffuser with struts to carry the turbine bearing loads out to the main structural casing. The material chosen for this was $\mathbb{I N 7 1 8}$. This material, however, does not meet current cost targets. An alternative structure linking the turbine module to the compressor module has been proposed and an initial evaluation made. The most significant advantages of this approach are potential cost savings associated with the elimination of the hot strut. The new structure is currently being modeled for stress and stiffness analysis. Initial analysis indicates that the module connecting frame will have the required stiffness.

CFD analysis has been performed on the exhaust collector. Results indicate that reduction of the axial dimension of the outlet will improve performance. This is in keeping with the requirements of the external support structure.

A finite element analysis of the spring cage for the turbine thrust bearing is being performed to obtain the required geometry to give the necessary spring rate.

Thrust Balance: Much effort has been expended on management of the engine thrust loads and providing for adequate thrust bearing life. Work on the thrust bearing load reduction is continuing. The design point thrust load has been reduced by reducing the stage 2 diaphragm hub seal and compressor discharge air seal diameters. Estimated thrust loads at off-design conditions have been performed using preliminary compressor and turbine static pressures generated by the aerothermal group. Preliminary engine start-up thrust analysis have also been performed, indicating a thrust reversal at approximately $60 \%$ speed.

Due to these issues, a thrust balance "piston" concept is being developed which would prevent major thrust overload problems during development and provide a means to fine tune the thrust in production engines destined for various ambient conditions. The balance piston would provide either decreased or increased thrust load, depending on need. Thrust tuning would be provided by a single orifice or some form of variable geometry. Sensitivity of the turbine seals to clearance and impact of skidding at low thrust loads on bearing life will be considered when determining the need for this balance piston concept.

Static Structure Thermal Analysis: Preliminary thermal analyses of the turbine nozzle case, centerbody, and thrust bearing housing have been completed to help support the design process. Problem areas identified are the nozzle case hook temperatures and the centerbody flange temperature. The introduction of the module connecting frame eliminates the centerbody issues. Turbine bearing cavity temperatures during steady-state operation are acceptable, and should be 
acceptable during soakback, due to the high heat transfer rate provided by oil pumped in at the bearing damper.

Rotor System: The work carried out over the past quarter focused on rolling element bearing design, squeeze film damper design and testing, and shaft rotordynamics.

The squeeze film damper (SFD) non-linear rotordynamic force coefficients necessitated a modification to Solar's in-house rotordynamic software "FERDA." A new routine was added to FERDA to calculate stiffness and damping coefficients based on the damper journal eccentric position. The routine calculates the force coefficients for short or long squeeze film dampers executing circular, centered orbits. The routine also allows selection of pi-film cavitation. This analysis works exclusively with unbalance response cases, and has been used extensively to design turbine SFD geometries.

The ATS-S rotordynamic model has been continually updated to reflect current changes in the rotor system. The updated model now contains speed dependent bearing stiffness characteristics and squeeze film damper geometries.

A modal analysis was completed on the gas producer turbine shaft. Solar has not used a gas producer turbine shaft (GPT) shaft in compression, and there were concerns that buckling, or a bellows mode vibration could occur. The shaft modal analysis, however, alleviated these concerns.

Work was also carried out on the ATS-S engine control system specifications. The vibration and bearing monitoring system, as well as the oil lubrication system was included in the rotordynamic area. Chip detection systems, which monitor the overall health of the rolling element bearings, are being evaluated for use in the ATS-S engine. The engine oil lubrication system requires 100 psi oil supply pressure into the SFD to prevent cavitation. This number may be lowered if damper tests show that cavitation will not cause a problem at lower supply pressures.

An alternative bearing design was considered that would use air lubricated wave bearings. This concept was rejected because the bearing pressures found in the ATS-S engine were too large for wave bearing applications.

Rolling Element Bearing Design: Roller bearings mounted in squeeze film dampers will support the ATS-S engine gas compressor section. The roller bearing design has been completed, and bearing drawings are currently being detailed. In an effort to reduce cost, the compressor inlet bearing and compressor discharge bearing are identical. Several bearing manufacturers are returning cost quotes and manufacturing lead times for the roller bearings.

High calculated thrust loads, coupled with the component life requirement for a B2 bearing, led to the design of a hybrid silicon nitride turbine thrust bearing. A silicon nitride ball diameter of $1 \frac{1}{8}$ " was found to possess acceptable life. This ball is currently available, and has been the subject of research at Pratt\&Whitney under the Advanced Research Projects Agency (ARPA) for possible use in an aircraft engine. However, since the ceramic balls do not have a proven track record in any commercial engine, a re-evaluation of the hybrid bearing design was undertaken, with a concerted effort to reduce the engine thrust loads. The thrust loads have subsequently been reduced significantly mostly by judicious seal design techniques. As a result, the steel ball bearing is now viewed as the bearing of choice for the S-engine. 
Squeeze Film Damper Design and Testing: Squeeze film dampers will be necessary on the Sengine bearings, in order to provide necessary damping at every bearing location. Solar has identified two bearing manufacturers with sufficient potential to design the gas compressor squeeze film dampers. The damping and stiffness characteristics have been determined for the gas compressor damper. Work on the turbine squeeze film damper is underway. The squirrel cage stiffness is being tuned, and final stiffness and damping coefficients will be determined when the thrust bearing design is complete.

A squeeze film damper test rig is also being constructed under WBS 42500 in order to verify all squeeze film damper force coefficients. The rig will also be used to adjust current theoretical squeeze film damper models in use at Solar Turbines. The SFD test rig lubrication system has been defined, and the hardware has been laid out in ProE. Final definition on the purchased damper and a hydraulic shaker to initiate tests are needed to complete the test rig layout.

\section{WBS 12200 - Package Mechanical Systems}

Preliminary discussions have been initiated with two generator manufacturers. A preliminary specification was issued, and the vendors are in the process of replying. We are currently looking at two configurations: open drip proof and water cooled.

The packaging group has decided to use a gearbox mounted to the frame instead of the integral gearbox/generator that was envisioned early in the design effort. A gearbox specification was created by design and several vendors were asked to respond. Currently the vendor designs are under review. The proposals are being evaluated for cost, size/weight, durability and efficiency. A preliminary review has focused on a parallel gearbox with near product specification efficiency and cost targets. Integration with the package design is critical to meeting overall package envelope requirements.

The Package group has been working with the recuperator group to design the mounting configuration for the recuperator. A preliminary design has been created. Final design is pending the release of recuperator drawings.

\section{WBS 12300 - Control and Indicating Systems}

A team was created to develop the control system specification for the "S." The draft specification is nearly complete, with a specification review planned for November, 1996. A final specification should be released shortly thereafter.

The lube oil system presents the greatest challenge. The incorporation of anti-friction bearings requires a departure from current design on industrial turbines. The packaging group is working with the engine design team to understand the requirements and create a suitable design.

The gas fuel system will incorporate an electric valve. Preliminary testing on a development engine has been completed. Solar has incorporated a prototype valve on a recent production engine, which will go to test in the last quarter of this year.

The start system will be based on Solar's current design - direct AC start. The system includes an electric motor mounted to the gearbox and a variable speed drive. A preliminary schematic has been created. 


\subsection{Technology Development Programs}

\section{WBS 19110 - Advanced Disk Cooling and Rotor Sealing}

This task consists of the development of advanced disk cooling techniques to support the ATS engine program objectives. Optimized cooling flow distributions using impingement cooling, firtree attachment cooling, and rim seal flows in CFD will be developed and tested for improved rotor/stator sealing and cooling techniques.

Program accomplishments to date include the following:

Fabrication of all components required for the rotating rig modifications was completed during the first quarter of 1996. The rig will be used to evaluate the optimization of advanced disk cooling and buffering concepts for improved turbine efficiencies through more effective use of cooling air. During the second quarter of 1996, instrumentation and testing for baseline data on disk cavity buffer air discharge techniques and characterization of hot gas ingress flows into disk cavities using $\mathrm{CO} 2$ tracing techniques were completed. Key observations to date include:

- The amount of hot gas ingress increases as disk speed increases, particularly noticeable at the intermediate radii.

- For a given disk speed and cooling flow rate, increasing the main flow rate increases the amount of hot gas ingress.

- Increasing the coolant flow rate, with everything else held constant, decreases the amount of hot gas ingress, particularly near the disk rim.

A disk to blade firtree attachment ANSYS model was completed for comparative thermal analysis of the standard and tapered gap firtree cooling concepts that are considered for application on the $S$ and $L$ engines.

An axisymmetric CFD model of the disk cavity was also completed for evaluating different disk secondary flows.

Pennsylvania State University completed assembly of a rotating rig for evaluating cooling penalties relative to different disk cooling schemes. Testing is now in process.

Overall resources for this project are currently ahead of the plan, both in labor and material, in order to effectively integrate the technologies into the engine component design for the first ATS engine to test.

\section{WBS 19120: Advanced Airfoil Cooling}

This task consists of the development of advanced turbine airfoil cooling techniques required to support the ATS engine program objectives. Turbine blade screw (vortex type) internal cooling concepts, endwall film cooling enhancements, optimized cooling flow distributions and external heat transfer measurement techniques in CFD will be developed and tested for advanced gas turbine performance. 
Program accomplishments to date include the following:

Screw Cooling: Various studies are in progress supported by university activities in evaluating vortex (screw type) turbine blade cooling concepts. The University of Utah is progressing in its contribution for understanding and quantifying screw cooling flow phenomenon. A flow facility was constructed and flow visualization has been completed. It was evident that secondary (Gortler) vortices exist even in the turbulent flow regime at Reynolds numbers comparable to turbine blade application. Surface static pressure measurements were obtained. Five hole pressure probe surveys have begun to determine local static pressure and velocity distributions.

MIT completed the proposal of the effect of rotation on a screw-shaped cooling swirl using a rotating rig to be performed between June 1996 and June 1997.

A 7x transparent model was fabricated for internal heat transfer measurements of screw cooled blade configurations using the liquid crystal technique.

In-house testing of prototype Mars blade screw cooling geometry is in process. The supplier (Howmet) has delivered cast CMSX-4 turbine blades with implemented screw cooling concepts and a set of cast CMSX-10 blades for validation testing in the hot cascade rig prior to rainbow testing with thermal paint in a Mars engine demonstration test. The analytically predicted metal surface temperatures show metal temperature reductions of more than $100^{\circ} \mathrm{F}$ is achieved at the leading edge, the pressure side near the trailing edge, and the tip region when compared to the current Mars engine data.

Optimized Cooling Flows: Three major phases of the Penn State University study have been fully defined in support of optimized cooling flow distributions. Phase 1 includes optimized disk impingement cooling concepts. Phase 2 determines optimized nozzle film cooling penalties. Phase 3 predicts minimized blade tip discharge losses. Fabrication of the test hardware is in process. In Phase 1, the aerodynamic penalties of coolant injection from rotor/stator gap of an axial flow turbine are being investigated using an updated PSU axial flow turbine research facility test rig.

Endwall Film Cooling: Secondary flow in gas turbine flow passages close to an endwall strongly affect the endwall and airfoil suction surface heat transfer and the aerodynamic losses. The University of Minnesota has been experimentally studying the phenomenon using an existing wind tunnel facility by evaluating gas turbine endwall flow control with boundary layer fences to reduce the secondary flow effects on the suction surface heat transfer, to eliminate endwall local peak heat transfer coefficient, and to reduce the aerodynamic losses associated with the secondary flow. Measurements to date have revealed that the fences can effectively block the cross-flows from the pressure surface to the suction surface close to the endwalls along the flow passage, reorient the vortices and suppress their growth, and move the passage vortex away from the suction surface.

The experiments also show that the fence can reduce the size of the triangular regions on the suction surface affected by the secondary flow and reduce the heat transfer coefficient within these regions. The suction surface film cooling in these triangular regions can be improved by applying the fences. The fence can reduce the endwall heat transfer coefficient and improve endwall film cooling by blocking the endwall cross-flows. The fence is expected to reduce the aerodynamic losses associated with the secondary flow. In this study the effects of the fences are not influenced significantly by the freestream turbulence intensity, a long fence is required when the freestream turbulence is high. 
It was shown that the fences are less effective at a higher Reynolds number (high inlet velocity).

The application of the boundary layer fences is a simple and economical method to reduce the airfoil suction surface and the endwall temperature without additional cooling and to reduce the aerodynamic losses associated with the secondary flow.

External Heat Transfer Measurements: In advancing the external heat transfer and film cooling effectiveness measurement techniques for hot cascade rigs, turbine nozzle components have been fabricated and instrumented for hot cascade testing. The rig assembly has been completed with measurements being evaluated to calibrate the existing Textan analytical code. Accurate predictions and measurements of gas side heat transfer and film cooling of turbine airfoils are critically important for durability of these components. Experimental validation of the existing analytical methods is an essential part of the cooling systems development. The water-cooled vane hot cascade transient heat transfer measurements and pressure sensitive paint film cooling measurements will assist in establishing improved methods for obtaining external heat transfer coefficients and film cooling effectiveness.

\section{WBS 19130 - Tip Clearance Control}

This task consists of designing and testing a turbine hot section thermal management system that provides improved blade tip clearance control in support of the ATS engine program objectives. The concepts will be demonstrated on the Saturn and Mars engines.

Program accomplishments to date include the following:

A transient thermal analysis for a semi-active blade tip clearance control system in a Saturn engine has been completed. Results indicated a potential turbine efficiency improvement of about $1 \%$ when cooling air supply to the nozzle case is diverted to the bleed valve during shutdown and following hot restart.

The major benefits from the semi-active tip clearance control system can be expected in simple cycle engines, including the L, as well as spinoff application to the Mars, Centaur, and Saturn engines. The Saturn engine demonstration test is still pending availability of a test bed.

\section{WBS 19210: ULP Technology Development}

The objective of this task is to conduct proof-of-concept and prototype combustor testing to support the ATS-S and L gas turbines. Testing is to be conducted at reduced scale in an existing Solar combustion rig in order to cost-effectively reduce development risk of the two full scale combustion systems. Potential ultra-low NOx combustors and fuel injectors will be evaluated to assess performance. Critical design parameters established through this rig testing will be used in the design of the full scale ATS-S and L engines.

Program accomplishments include the following:

To date, a prototype ATS injector and combustor can have been designed, fabricated and subjected to initial rig tests. Although the hardware was designed prior to the refinements in configuration of the S-engine in early 1996, the hardware is still sufficiently generic to provide considerable insight 
into the design details necessary to achieve ultra-low emissions.

The ATS injector is similar in concept to Solar's SoLoNOx injectors being a piloted, axially swirled, premixing injector. Fuel injection is by means of multiple, radial fuel spokes located downstream of the main air swirler. Improvements to the ATS injector include the use of an improved swirl blade design for better aerodynamics and the provision for a longer premixing channel.

The ATS injector was evaluated in conjunction with an eight inch diameter, trip-strip cooled cylindrical liner. The liner is discussed in more detail below under Task 19240.

The injector and liner were evaluated in a combustion test rig at Solar at inlet temperatures from $600^{\circ} \mathrm{F}$ to $1100^{\circ} \mathrm{F}$. NOx and $\mathrm{CO}$ emissions below $10 \mathrm{ppm}$ were achieved over the range of inlet temperatures investigated. At the highest inlet temperatures, however, the operating range over which ultra-low emissions were achieved was quite narrow.

This testing verified the basic ultra-low emissions performance of a potential ATS injector design. In addition, the test data has allowed the quantification of an acceptable combustor loading parameter (Btu/hr-ft3-atm) for low emissions in the full scale ATS-S and L engines.

On a subcontract basis, the Caterpillar Technical Center is conducting supportive studies in the area of low emissions combustion. Most of the activity this year has been funded by Caterpillar alone and has focused on the fabrication and installation of a combustion test rig at the Technical Center. This test rig will allow subscale combustion hardware evaluations to be performed.

As part of the ATS program, the Technical Center has completed a CFD analysis of a typical SoLoNOx fuel injector. Its findings suggest that improvements to the fuel/air mixing can be achieved by modifications to the injection orifices in the injector fuel spokes. A single injector incorporating the improved fuel distribution has been fabricated. Once the test rig has been commissioned, tests will be conducted comparing the emissions from a standard injector and from the modified injector.

Other work to be performed by the Technical Center in the future involves support in the area of advanced liner cooling.

\section{WBS 19220 - Catalytic Combustion}

The objective of this task is to continue the development efforts initiated in Phase 2 in order to advance catalytic combustion technology to engine readiness by the end of Phase 3. Initial testing will be conducted on a single-can full scale test rig. Based on test results, a set of full scale engine hardware will be designed and evaluated in atmospheric pressure and high pressure combustion test rigs. Upon completion of rig testing, the catalytic combustion system will be integrated into an ATS "S" engine.

Catalytic combustion for gas turbine applications is a relatively unproven technology. While the potential benefits on pollutant emissions are attractive, system development issues are quite formidable. These issues include improved fuel-air premixing, catalyst design and durability, engine start-up using conventional burners, transition to/from catalyst operation, and engine controls. Progressive development and evaluation of the technology in subscale tests, followed by single can full scale tests, and finally at engine scale will demonstrate the practical feasibility of the technology 
to achieve ultra-low emissions in gas turbines.

Under Phase 2 of the ATS program, subscale evaluation of catalytic reactors was completed (December, 1995-for details see Topical report for Task 8.2). Based on subscale test results, a single can full scale catalytic combustion system that integrates the various modules of a catalytic combustor was designed and fabricated. This work was completed under Phase 2 of the program (April, 1996-for details see Topical report for Task 8.5). Additional work on catalytic combustion technology development has continued under Phase 3 since May, 1996. Program accomplishments to date include the following:

Development efforts concentrated on making the full scale system operational. The rig was made operational in the following steps:

- Assembly of the test rig, installation and calibration of test cell instrumentation, installation - of rig plumbing (fuel supply lines, cooling water supply, etc.), and set-up of valve actuator controls was completed.

- Cold air flow tests were conducted to shakedown the test rig and to verify mechanical actuation of flow control valves and the accuracy of rig instrumentation. Fuel concentration measurements were conducted at the inlet to the catalyst (to characterize the quality of premixing of fuel and air) using an instrumented (30 probes) catalyst module supplied by Catalytica. Based on initial measurements, the fuel injectors were modified and premixing measurements were performed again.

- Air flow tests using preheated air were initiated after installation of the expansion bellows in the exhaust. At elevated combustor inlet temperatures, all flow regulating valves were found to "stick". Design modifications and hardware changes were completed to prevent "sticking" of valves. Several flow tests were performed at $595^{\circ} \mathrm{C}$ (maximum obtainable air preheat temperature on rig) to ensure the operability of the valves at these inlet temperatures.

- $\quad$ Premixing measurements were conducted under various simulated gas turbine operating conditions. Modifications to the design of premixer were necessary to obtain levels of premixing within catalyst specifications.

- The rig was disassembled and effective flow areas of components were determined on a cold flow bench. This was necessary due to the modifications to the rig since the initial assembly. The rig was then re-assembled with an active catalyst bed (replacing the instrumented catalyst module used for premixing measurements) and readied for combustion tests.

- Preliminary combustion tests with a single stage catalyst were completed. Unlike the test results on the $2 \mathrm{in}$. subscale rig at Catalytica, the fuel-air turndown of the catalyst alone was not sufficient to meet emissions goals through the 50 to $100 \%$ load range (this is attributed to better premixing obtained in the subscale test rig). However, by using the variable geometry valve at the inlet to the catalyst, emissions goals were met at 50,60,70,80, 90 and $100 \%$ load (test points). Consistent with subscale test results, the NOx emissions were less than 3 ppmv (corrected to $15 \% \mathrm{O}_{2}$ ) with $\mathrm{CO}$ and UHC less than $10 \mathrm{ppmv}$ at the above test points. Measured combustor exit temperatures were relatively uniform $(\sim 12 \%$ peak to peak variation). Following the catalyst tests, the start-up (and part-load) injector was ignited and 
operated at several part load $(<50 \%)$ operating conditions.

Development efforts will now be directed at the systematic evaluation of the following:
a. Transition of the system from lean premixed (LP) mode of operation to catalytic mode of operation.
b. Effect of maintaining a lean-premixed pilot flame on catalyst emissions.
c. Effect of air leakage on catalyst emissions.
d. Effectiveness of the "trip strip" cooling in maintaining desired combustor wall temperatures.
e. Improvement of fuel-air premixing.

At the present time, the evaluation of the single can full scale rig is expected to be complete in the December '96/January '97 time frame.

Catalytic Work: Solar is continuing to work with Catalytica on the design and fabrication of catalysts for testing in the single can full scale rig. Work performed by Catalytica (under a Solar subcontract) during the report period is summarized below:

- Combustor Cycle Calculations: Combustor cycle calculations for the current ATS "S"cycle were performed and used as input for catalyst design. In light of the (almost) constant combustor inlet temperature between 50 and $100 \%$ load, it may be possible to develop a catalyst capable of providing sufficient fuel air turndown over this load range without the need for variable geometry.

- CFD Modeling of Film Cooling Air Effects on UHC and CO Emissions: This work is being performed through a Catalytica subcontract to Air Flow Sciences. Initial work incorporated detailed kinetic schemes (C1-C2 hydrocarbon oxidation with nitrogen chemistry using the GRI 2.11 mechanism). Problems of code convergence were encountered and substantial work was required to obtain convergence. However, the computational expense involved while using the detailed kinetics model necessitates the current use of a reduced chemical mechanism in the calculations. A topical report is expected soon.

- Catalyst Design, Rig Testing and Development: To date, three catalyst designs have been developed through subscale testing in a high pressure test rig at Catalytica. The current catalyst design is based on the ATS "S" engine cycle. Subscale tests at Catalytica using this design have shown the possibility of sufficient fuel-air turndown between 50 and $100 \%$ engine load. (This aspect will be further evaluated in the full scale tests at Solar).

- Catalytic Combustor Reactor Container/Support Mechanical Design: An atmospheric pressure catalyst container test facility has been set up at Catalytica in order to study various catalyst container candidate designs (effects of differential expansion of catalyst and container etc.). These tests will be performed under conditions simulating engine air flow rates and operating temperatures. Initial shakedown tests have revealed a problem with the fuel pump, which is being addressed.

- Full Scale Catalyst Production and Assembly: A single-stage full scale catalyst (designed for the current " $\mathrm{S}$ " engine cycle) was fabricated and tested in the full scale test rig at Solar. 
Preliminary results of the testing have been described above.

In general, the subtasks being performed by Catalytica are progressing on schedule. The 200 hour durability testing of a subscale catalyst under simulated design conditions (scheduled for July, '96), has been postponed to allow further development and optimization of the catalyst design. Postponement of the durability testing at the present time is not expected to affect the progress of the other subtasks.

A program update meeting between Solar and Catalytica was held in August, '96. Program schedules were reviewed by the Solar ATS combustion team and Catalytica. The Catalytica development schedule is consistent with the overall development milestones at Solar. As a result of the discussions, the following additional tasks were added to the scope of the Catalytica subcontract:

- Solar has suggested additional testing at Catalytica to study the effects of various contaminants on catalyst performance. Suggested contaminants include a combination of sodium and sulfur, vanadium, and engine lubricating oils. The information will be generated through accelerated contaminant testing at Catalytica.

- In response to increased interest in air toxics emissions in the state of California (in particular, materials such as formaldehydes), Solar and Catalytica have agreed to characterize air toxics emissions from catalytic combustion systems. Solar and Catalytica have agreed on a test procedure to investigate if the use of catalytic combustion may provide potential reductions in air toxics emissions.

\section{WBS 19230: Advanced Combustion Controls}

This task has two objectives. The first is to evaluate a variable geometry (VG) injector design that will extend the engine operating range over which low emissions are achieved. The injector concept will be evaluated in conjunction with a Solar Centaur 50S. Testing of the injector in a full scale rig and an in-house engine will be performed. In addition to injector testing, an actuation system to control the multiple VG injectors will also be demonstrated. The second objective of this task is to demonstrate an exhaust gas $\mathrm{CO}$ sensor that can be used to control the VG injectors. A field test of a $\mathrm{CO}$ unit will be conducted to establish system durability. A second unit will be used in conjunction with the VG injectors. The $\mathrm{CO}$ sensor will be used to provide a feed-back control signal to the injectors to optimize emissions at all operating conditions.

Early evaluation of the VG injector concept will establish the concept's viability for the ATS engines. Testing of the $\mathrm{CO}$ sensor will demonstrate the viability of a gas turbine control system based on a closed-loop emissions feedback signal.

Program accomplishments to date include the following:

Actuation hardware for an existing set of VG fuel injectors for the Centaur $50 \mathrm{~S}$ gas turbine was fabricated. The actuation system is comprised of a unison ring that is driven by a single electric actuator. The ring simultaneously drives the set of twelve fuel injectors to vary the primary zone air flow as engine load varies. By keeping the primary zone flame temperature essentially constant, low 
emissions can be achieved over a wider range of engine loads.

The VG systems (injectors and actuation hardware) were installed on a full scale Centaur test rig. Testing was conducted at near Centaur 50S conditions with good results. SoLoNOx emissions levels of below $25 \mathrm{ppm}$ NOx and $50 \mathrm{ppm}$ CO were achieved over a range of approximately $75-100 \%$ load.

Presently, minor design modifications are being made to the actuation system. Following hardware modification, the VG system will be evaluated in an in-house Centaur engine test.

The first CEMCAT CO sensing unit was installed at a customer's Mars engine site for durability testing. This unit has been operational since February. The unit is running in parallel with a conventional CEMs unit. Comparisons of the emissions data from the two systems are showing good agreement.

The second CEMCAT unit has been undergoing evaluation at Solar since June. Zero and 100\% span stability tests show acceptable performance. Interference tests have been completed. In general the CEMCAT unit is functioning well.

Recently the CEMCAT product line was purchased by Monitor Laboratories. The unit at Solar has been returned to Monitor Labs for upgrades to the system software and the inclusion of a second CO sensing element. When returned to Solar, this CEMCAT will be put into operation with the VG injectors. Integration of the CEMCAT into the engine control system will be started.

\section{WBS 19240: Advanced Liner Cooling}

The objective of this task is to establish the effectiveness of various advanced liner cooling concepts to support the design of the ATS gas turbines. The high operating temperatures and low emissions goals of the ATS-S and L engines will require the use of advanced combustor liner cooling techniques. In this task, advanced concepts will be identified and evaluated in a heat transfer rig and in a subscale combustion rig. Quantitative heat transfer data established through the rig tests will directly support the design of the full scale combustors for the ATS engines.

Through the early definition of effective liner cooling techniques, the design of the ATS-S and L combustor liners will be expedited. Rig tests utilizing the selected liner cooling concept will allow quantification of heat transfer effectiveness, thus reducing the technical risk associated with full scale liner development.

The focus of this task has been to define liner cooling configurations that do not require air injection through the liner walls. Cooling air injection can be a significant contributor to $\mathrm{CO}$ emissions through quenching of the flame near the combustor wall. By reducing $\mathrm{CO}$ emissions, the primary zone flame temperature can be reduced with the result being reduced NOx emissions.

Program accomplishments to date include the following:

A literature survey was conducted to identify various back-side cooling configurations and assess their heat transfer effectiveness. Based on this survey and a considerable amount of prior work conducted at Solar, a "trip-strip"-based configuration was selected for initial evaluation. 
An eight inch diameter can combustor using backside, trip-strip cooling was designed and fabricated. An identical can without trip strips was also fabricated. Rig testing of the trip-strip liner was conducted to allow an assessment of the enhanced cooling configuration.

Initial testing of the trip-strip liner was conducted at various inlet temperatures up to $1100^{\circ} \mathrm{F}$ and a pressure of approximately 100 psig. The testing was conducted using the advanced injector developed for Task 19210. The test results indicate that backside cooling is an effective means of maintaining reasonable liner temperatures. Testing demonstrated NOx emissions below $10 \mathrm{ppm}$ with acceptable liner temperatures and $\mathrm{CO}$ emissions. While the test results are very positive, additional testing will be conducted to fully characterize the combustor performance.

Testing of the second non-trip strip liner is scheduled to allow a direct comparison of the effectiveness of the trip strips in augmenting liner cooling. This second combustor will then be used to assess other back-side cooling configurations.

In addition to the combustor rig testing, work is also underway fabricating test specimens for evaluation in Solar's heat transfer rig. In this rig, quantitative heat transfer data can be gathered for different backside cooling configurations using small test specimens. Through the rig testing, the trip strip (or other geometry) configuration can be optimized. The heat transfer rig results will directly support the heat transfer calculations needed to design the full scale ATS-S and L combustors.

\section{WBS 19300: Ceramic and Composite Materials Development}

The objective of this program is to develop advanced high temperature materials for use in the ATS engines. This is a logical follow on to the Ceramic Stationary Gas Turbine (CSGT) program which Solar has been performing for DOE over the last several years. Ceramic and composite components which are successfully demonstrated in the CSGT program will be redesigned for use in the ATS engines. They will be upgraded and improved where necessary to support the higher firing temperatures planned for ATS.

Ceramic and composite materials offer potential benefits to the ATS engines toward meeting all major program goals: high thermal efficiency, low exhaust emissions, and low life cycle cost. Use of ceramic blades, nozzles, and tip shoes in the hot turbine stages will reduce cooling air flow requirements, allowing more hot air for expansion through the turbine, resulting in increased output power and efficiency. Use of ceramic composite combustor liners will allow the combustor wall to operate at a higher temperature, which reduces the quenching of the carbon monoxide $(\mathrm{CO})$ to carbon dioxide (CO2) reaction along the walls, and thereby reduces the $\mathrm{CO}$ emissions substantially. Having a hot wall also allows the combustor to operate at a leaner mixture, which reduces primary zone temperature and NOx emissions.

Use of ceramic and composite hot components may provide greater component life than the metal parts they replace. When the production costs of the ceramic pieces can be reduced to equal those of the metal pieces, the added component life will reduce the life cycle cost of those components.

The benefits of ceramics as applied to various engine components and program accomplishments to date are addressed in WBS 19310 through 19360 below. 


\section{WBS 19310 - Ceramic Combustor Materials}

A combustor to nozzle transition duct is being fabricated by BF Goodrich Aerospace (BFG) in this task. BFG's tooling subcontractor initially had some difficulties with the IGES file model of the part, but the tool was completed in September, 1996. Lay up of the first of three ducts was completed during the first week of October. The fiber architecture for this part is a triaxial braid. Chemical Vapor Infiltration (CVI) of the part was started in October. The second part is being fabricated from a biaxially braided preform. It is currently being laid up. BFG will send photographs of the lay up process to Solar. The parts are on schedule for delivery at the end of October, 1996.

Coupon testing for life prediction data was started at BFG's Brecksville Research Center. The testing is scheduled to be completed by the end of October, 1996.

Introduction of a ceramic combustor liner into the S-Engine was replanned because the success of the Continuous Fiber Ceramic Composite (CFCC) design in the CSGT program eliminated the need for an extensive design effort for the S-Engine combustor.

Coupon test plans were outlined to generate data for stress analysis and life prediction. Solar is working with suppliers, Oak Ridge National Labs, and University of Dayton Research Institute to test the most promising CFCC materials.

\section{WBS 19320 - Ceramic Tip Shoe}

In order to gain the full benefits of using uncooled ceramic first stage turbine blades, the tip clearance for the ceramic blades must not be greater than the tip clearance for metallic blades. Opening the tip clearance would result in a reduction in efficiency, which is not acceptable. To ensure consistent tip clearances with ceramic blades, an examination of abradable tip shoe coatings for use with ceramic blades has been initiated.

The abradable tip shoe materials will be tested in Solar's rub rig test facility using full length NT-164 (Norton Advanced Ceramics) silicon nitride turbine blades purchased under Solar's DOE sponsored CSGT program. The NT-164 blades were previously proof tested to $125 \%$ of design stress and tested in the CSGT Centaur 50 engine. These blades were not selected for the 4000 hour field demonstration test of this engine, and are available for abradability testing.

Abradable tip shoe materials to be tested include coated metallic tip shoes and porous monolithic ceramic tip shoe materials. The coatings will include baseline metallic tip shoes currently used in Solar's production engines as well as porous ceramic thermal barrier type coatings. The tip shoe drawings for testing abradable materials in the rub rig test facility have been completed. The drawings have been sent to various suppliers and the hardware will be ready for testing in the last quarter of 1996. A disk drawing for testing full length ceramic dovetail blades in the rub rig test facility has also been completed and is currently being fabricated. 


\section{WBS 19330 - Ceramic Bushings/Ball Bearings}

Very little effort was expended on this task during fiscal year 1996. The ceramic bushing development task became unnecessary when the variable area turbine nozzle was not included in either of the ATS engine concept designs.

A ceramic ball bearing was evaluated as a possible thrust bearing for the $S$-Engine. The potential life advantage of the ceramic ball over a steel ball did not outweigh the risk of depending on the largest ceramic ball bearing known to exist. Design of the ceramic ball bearing has been placed on hold, in favor of the steel ball bearing.

\section{WBS 19340 - Interstage Seal Ring}

Use of a low expansion ceramic ring to provide sealing of the turbine disk cooling air offers the prospect for better sealing using a low weight component. This, in combination with the potential of lower cost, makes ceramic matrix composite rings very attractive when compared to their metallic counterparts. Another gas turbine manufacturer is currently working on such a seal concept with some success. Solar is a subcontractor to Dow Corning as part of the CFCC initiative. The seal concept under consideration will have knife edges rubbing into an abradable surface on the inner diameter. Two abradable coating concepts have been attempted to date. Drawings of attachment concepts have been sent to. Dow Corning. Fruitful discussions aimed at obtaining a balance between ease of fabrication and function have resulted in some modification to the concept. Rub tests (preliminary) are planned in the next quarter.

The use of the interstage seal ring made of CFCC has been recommended for a later build of the "S" engine. Activities necessary to complement the first engine test include design of interstage seal rings; abradability testing; long term material testing; and rig testing.

\section{WBS 19350 - Ceramic Turbine Blades}

Effort regarding the ceramic blades was concentrated on the issue of blade tip clearance and the ability of a ceramic blade to rub against a tip shoe, without blade damage. The related technology research is actually the coating on the tip shoe. This effort was described under task 19320.

\section{WBS 19360 - Ceramic Turbine Nozzles}

First and second stage silicon nitride nozzles have been studied in a number of gas turbine development programs. The Allied Signal program has been the most successful with its component accumulating excess of 2 million hours of service life. Solar's CSGT program envisions testing a set of 42 first stage ceramic nozzles for 4000 hours at TRIT of $2050^{\circ} \mathrm{F}$, in a Centaur 50 engine at an end user site in Bakersfield, California. Design of the first stage retrofit ceramic nozzle has undergone considerable innovation, in order that the peak stress on the part be below $30 \mathrm{ksi}$. Based on a combustor pattern factor of 0.2 , it is predicted that the worst case peak temperature on any nozzle will be $2350^{\circ} \mathrm{F}$.

Extensive long term testing has been carried out on the primary silicon nitride candidate, SN88 from NGK, SN253 from Kyocera and Hexoloy SA silicon carbide. This testing resulted in the down selection of SN253 and Hexoloy SA. Based on this testing it is recommended that for 30,000 hours 
life at $2350^{\circ} \mathrm{F}, \mathrm{SN} 88$ nozzles should not be subjected to a peak stresses greater than $25 \mathrm{ksi}$. A new material, AS800 (silicon nitride) made by Allied Signals Ceramic Company has shown promise for this application in preliminary material characterization.

A nozzle thermal proof rig has become operational to qualify SN88 nozzles for the engine test. This thermal proof rig is capable of generating a gradient of $1050^{\circ} \mathrm{F}$ from the mid-span of the airfoil to the shroud with no forced air cooling. A mechanical proof rig to qualify the nozzles for gas loading has also been fabricated.

The 4000 hour CSGT engine test will be the most valuable indicator of feasibility of this material as a candidate for the ATS nozzle. Other activities deemed necessary to complement the engine test include material down selection, conditioning, NASA exposure testing, cyclic fatigue testing, and dynamic fatigue testing.

Material Downselection: SN88 from NGK has been chosen as the material of choice. This silicon nitride has shown the greatest balance of high fracture toughness and good strength up to $1300^{\circ} \mathrm{F}$. The stress rupture life of the SN88 nozzle has been shown to be higher than that of either SN253 or Hexoloy SA. NGK has shown the capability to manufacture complex parts, as evidenced by its timely delivery of the first generation of the CSGT nozzle.

A second material, that was not evaluated for the nozzle application under the CSGT program is the AS800 silicon nitride. This material has shown promise in preliminary characterization at Oak Ridge National Laboratories and UDRI. Material data being collected by the Universities and National Labs will provide us with additional information.

Conditioning: A conditioned SN88 tensile specimen has been tested at a stress of $28 \mathrm{ksi}$ ( 193 $\mathrm{MPa})$ and $1288^{\circ} \mathrm{C}\left(2350^{\circ} \mathrm{F}\right)$. The conditioning treatment may have resulted in the blunting of flaws. The specimen failed after 8700 hours of testing, much higher than the life expected for an unconditioned specimen (predicted life is 6500 hours). A series of tests at a higher stress is planned to fine tune the conditioning treatment.

NASA Exposure Test: The effect of combustor gas pressure, velocity and composition can be quite different from exposure to air. A study to establish the relative degradation in the flexural strength of SN88 and AS800 after exposure to this high pressure environment, would give us the capability to predict the life of these nozzles in the turbine environment more accurately. A purchase order has been issued to procure specimens from both the suppliers for testing NASA's High Pressure Burner rig.

Cyclic Fatigue and Dynamic Fatigue Tests: The effect of vibrational influences on the life of the nozzle airfoil is considered minimal. However, at the interface of the nozzle attachment features and the adjoining metallic substructure, this effect could be pronounced. Cyclic testing that simulates cage conditions have been planned on tensile specimens.

\section{WBS 19410 - Forged Turbine Disk Development}

The goal of this task is to investigate next-generation forged disk materials with higher rim operating temperature capabilities than currently available alloys Waspaloy and Inconel 718. The task involves developing cost effective forging and heat treating techniques for a new high strength disk material, 
Udimet Alloy 720. The initial screening tests and prototype demonstration phases of the Udimet 720 program will be carried out with two forging suppliers in parallel, Wyman Gordon Company and Ladish Company. A downselection will occur based on technical achievements and cost analysis. The purpose of carrying two suppliers is to reduce risk since timely delivery of engine hardware is critical to the ATS-S program and to provide a sound basis for a competitor assessment for procurement. The downselected company will optimize the forging process in subsequent phases and, in conjunction with Solar, complete a materials database to support future designs and life prediction efforts.

A significant performance improvement has been predicted if the turbine cooling flow requirements to the hot section can be reduced. This task will result in the development of disk materials which can operate at higher temperatures, thus allowing reduced cooling. The program will also confirm whether the resulting efficiency gains will offset the cost of an advanced disk alloy. Solar and the ATS Program will benefit indirectly from the years of DOD research on advanced disk alloys performed by Wyman and Ladish. Thus, an underlying goal is to transfer as much publicly available forged disk technology from that research into commercially viable forged products for industrial gas turbines.

Benefits of a next-generation disk material include:

- ATS-S uncooled second stage rotor - Achieving the engine efficiency goals of the ATS-S relies on the design of an uncooled second stage in order to minimize parasitic losses. Currently available disk materials would not perform.

- $\quad$ ATS-L Engine - Advanced disk material would have immediate application because of similar requirements as ATS-S for minimizing cooling flows for improved efficiency.

- $\quad$ CSGT - Higher disk rim temperatures is considered an enabling technology for the use of ceramics by reducing stresses driven by thermal gradients.

- Technology spin-off - Solar's existing product line could benefit from the higher temperature and/or longer life of the next-generation disk alloy.

Program accomplishments to date include the following:

The candidate uncooled second stage ATS-S disk concept was designed, and initial stress analysis has been completed. Analysis showed that coarse grain Udimet Alloy 720 would fulfill ATS-S life requirements if property goals of the program were attained. A clear path to integrating Udimet 720 into the 1st ATS-S engines was defined.

A detailed request for quotations (RFQ) was delivered to forging suppliers, including mechanical property goals of the development program. Wyman Gordon submitted a proposal and work is now under way. A proposal from Ladish Company is expected in October.

A subcontract to Wyman Gordon was negotiated and released for phase I screening tests against design requirements, and also to perform a complete literature survey on the subject of advanced turbine disk materials and production. 
Prototype forgings produced from - 150 mesh Udimet Alloy 720 powder were heat treated by Wyman Gordon, and experiments confirmed that the desired coarse grain structure could be attained. Two grain size variants were successfully made. The material development thus far has illustrated a large process window for the powder product, much greater than cast/wrought product forms of U720.

A series of mechanical property screening tests of prototype coarse grain Udimet Alloy 720 were completed by Wyman Gordon. The matrix included tensile, creep-rupture and Low Cycle Fatigue (LCF) tests at temperatures of interest. Present results are favorable compared to previous data, and when extrapolated indicate that coarse grain Udimet Alloy 720 has a strong potential of meeting the ATS-S 2nd stage disk rupture requirements.

Udimet Alloy 720 raw material was located through Special Metals, Inc. to support the remainder of Wyman Gordon forging process development phases and initial engine hardware production. A purchase order for the material was completed, with extrusion of a 4159 pounds, 9.25 " diameter billet scheduled for November 1996.

\section{WBS 19420 - Dual-Alloy Turbine Disk Development}

This task will continue development of the dual-alloy disk concept initiated under ATS Phase 2, Task 8.4 in a collaboration with Howmet Corporation. The program has similar goals as the forged disk development WBS 19410, i.e., higher turbine disk rim operating temperature capability for reduced cooling and improved cycle efficiency. However, the temperature goals of the dual-alloy program are more aggressive and higher risk than the forged disk approach. The dual-alloy concept involves bonding a disk rim fabricated from creep resistant Mar-M-247 cast superalloy to a high strength forged $\mathrm{P} / \mathrm{M}$ Udimet 720 hub material. A solid-to-solid HIP bonding process was shown to have promise in ATS Phase 2, although work remained in developing process parameters to maximize bond-line strength and ductility. The ATS Phase 3 program is carrying this effort forward with the goal of achieving mechanical properties acceptable to design engineering for ATS conditions, and defining a path to production of dual-alloy rotors. The program will produce a materials property database to support life analysis of the rotor. A detailed cost analysis will be performed to confirm the economic viability of the concept.

There is major potential for engine performance improvement if the turbine cooling flow requirements to the hot section components can be reduced. The dual-alloy concept is a relatively high risk - high pay off technology development designed to achieve this goal. If successful in terms of both technical and economic (component cost) aspects, there could be strong spin-off potential to other turbine products and uprate programs.

Program accomplishments to date include the following:

A study of the effect of diffusion cycle time and temperature on bond-line properties was completed. The study was aimed at addressing some of the ductility and bond-line strength issues uncovered in ATS Phase 2 Task 8.4 when bonded at $2050^{\circ} \mathrm{F}$. The HIP bonded structures were exposed at $2165^{\circ} \mathrm{F} / 4 \mathrm{~h}, 2225^{\circ} \mathrm{F} / 4 \mathrm{~h}$ and $2225 \mathrm{~F} / 8 \mathrm{~h}$. In addition, the influence of these higher temperature diffusion cycles on the LCF properties of P/M Udimet 720 hub material was examined. The main conclusions were:

- The Mar-M-247 rim material grain size was unaffected by the higher temperature thermal 
exposures at $2165^{\circ} \mathrm{F}$ and $2225 \mathrm{~F}$, as expected. The P/M Udimet Alloy 720 grain size coarsened from ASTM 10 to ASTM 7.5/8.0 after thermal exposure.

- Despite the coarsened grain size, the P/M Udimet Alloy 720 maintained exceptional Low Cycle Fatigue (LCF) strength. This indicates the P/M material has a wide and relatively insensitive processing window which allows great flexibility in HIP bond processing.

- Depth of diffusion zones of bonded material after $2165^{\circ} \mathrm{F}$ and $2225^{\circ} \mathrm{F}$ for 4 hour thermal exposures were 75 and 85 microns respectively, whereas 100 micron diffusion zones resulted after the $2225^{\circ} \mathrm{F} / 8 \mathrm{~h}$ exposure. The 100 micron diffusion left an area adjacent to the bond-line which was lean in strengthening elements. This resulted in reduced strength and occasional bondline failures, which makes the $2225^{\circ} \mathrm{F} / 8 \mathrm{hr}$ exposure undesirable.

- Higher $70 \mathrm{~F}$ ultimate strength and ductility with equivalent $0.2 \%$ yield strength in HIP bonded Mar-M-247/PM U720 were exhibited after $2165^{\circ} \mathrm{F} / 4 \mathrm{~h}$ compared to $2225^{\circ} \mathrm{F} / 4 \mathrm{~h}$ and $2225 \mathrm{~F} / 8 \mathrm{~h}$ materials.

- Higher creep rupture properties at $1300^{\circ} \mathrm{F} / 100 \mathrm{ksi}$ were achieved after $2165 \mathrm{~F} / 4 \mathrm{~h}$. The elongations at failure measured in accelerated creep rupture tests were relatively low $(<1.4 \%)$. Metallograhic and microprobe examination revealed that the low ductility was probably attributable to the presence of continuous grain boundary precipitates rich in rare earth and refractory elements hafnium, tungsten, and tantalum.

\section{WBS 19430 - CMSX-10 Airfoil Alloy}

The goal of this task is to introduce CMSX-10 third generation single crystal alloy to the ATS-S first stage turbine blade design. Castability trials and heat treat optimization will be performed in a cooperative program with Howmet Corporation, leading production readiness of the alloy. Coatings evaluations will be completed as part of the program. A design database of mechanical and physical properties will be developed. A financial analysis will be performed to determine the cost of the alloy in full production and to confirm that the anticipated increase in alloy cost is supported by the enhanced performance/life of the blade. This task will also help ensure synergy with the Howmet/Solar/ORNL Land Based Gas Turbine Casting Initiative.

CMSX-10 alloy will provide a $50-60^{\circ} \mathrm{F}$ operating temperature increase relative to the current best airfoil material CMSX-4. This temperature capability can be used to increase firing temperature/reduce cooling requirements resulting in increased cycle efficiency. The benefits of CMSX-10 include:

- $\quad$ ATS-S first stage blade - Early calculations indicate that CMSX-4 is marginal in providing the minimum one overhaul life requirement for ATS-S. CMSX-10 has the potential to allow two or more overhaul cycles.

- ATS-L Engine - CMSX-10 is likely to have immediate application in ATS-L first and potentially second stage turbine rotors.

- Technology Spin-off - Uprates of Solar's existing product line could benefit from the higher 
temperature and/or longer life of the CMSX-10 alloy.

Program accomplishments to date include the following:

The ATS-S 1st stage blade design is proceeding, and the stress/thermal analysis is clearly showing the performance advantages of CMSX-10. The design effort and technology development program are well integrated in order to be production ready for the first ATS-S engines.

An initial cost analysis of CMSX-10 was completed by Howmet using the Mars first stage blade (CMSX-4) as a baseline. CMSX-10 appears to be a good value because of the improved life (2 overhauls) afforded by the alloy.

A program plan was completed by Solar/Howmet, and raw material for casting trials and mechanical test bar molds was purchased from Cannon-Muskegon.

Casting trials of CMSX-10 were completed by Howmet using existing Mars first blade tooling. Two molds of blades were cast. Areas of investigation included core and shell ceramic systems, casting parameters, solution heat treatment, foundry processing, non-destructive inspection (NDI), and yield projections. Howmet now has a high degree of confidence in producing CMSX-10. In summary:

- Two shell systems were evaluated in the casting trials, and the "standard" coat system for CMSX-4 was suitable for CMSX-10.

- An existing core material used for CMSX-4 performed well with CMSX-10, no issues with core removal were found.

- Solution heat treat response was acceptable with $>99 \%$ gamma prime solutioning observed. Cooling rate effects are being investigated.

- $\quad$ Casting parameters produced acceptable grain yield. Existing blade processing systems will be satisfactory in production.

- Level of alloy depletion and metal/mold/core reaction was minimal.

- NDI yield results were very good.

A small testing plan/matrix was devised for the initial 22 bars, 6 "long $\times 0.5^{\prime \prime}$ diameter, produced in the casting trials. These bars will be cut in half to yield 44 test specimens. Howmet is proceeding with machining, then tensile and creep-rupture testing at the Whitehall facility. A larger follow-on test matrix is being formulated, and will include Low Cycle Fatigue $(\mathrm{LCF})$ and High Cycle Fatigue (HCF) testing to support the first stage blade design. Results will be stored in a central database, called M-Vision, for use by design in the future.

A plan to evaluate coating techniques for CMSX-10 has been formulated. Raw material for screening tests of candidate coatings was received from Cannon-Muskegon, Inc. This task is being coordinated closely with WBS 19730, Alloy Coating Systems, to ensure all aspects of the blade design, casting process, life requirements and mechanical property impact are considered with the coating. 


\section{WBS 19440 - Low CTE Materials Development}

Dimensional control of the turbine hot section is a critical issue when optimizing engine efficiency. Low coefficient of thermal expansion (CTE) alloys are typically used for this purpose. This task will explore the application of second generation Low Thermal Expansion (CTE) alloys in the ATS-S and ATS-L designs for improved durability and reduced life cycle cost. This task will address forging process development for a new 2nd generation low CTE alloy, Haynes 242 . The development task will also address heat treatment and machining aspects of the new alloy. The program will culminate in delivering and testing engine hardware in the ATS engine.

The Low CTE development effort will provide an important alternative to the current low CTE alloy Incoloy 903 used in past designs. Incoloy 903 has attractive expansion characteristics; however, it is a problematic material because it is not readily available, is difficult to forge, is restricted in braze processing temperature, is not weldable, and the finished component requires aluminide coating in applications above $1000^{\circ} \mathrm{F}$. Haynes alloy 242 is being evaluated to improve, or eliminate, each of these issues. Perhaps most importantly, Haynes 242 can operate uncoated thus improving the durability and life cycle cost of the ATS engine. The technology could be easily transferable to future engine designs as well.

Program accomplishments to date include the following:

Haynes alloy 242 was down selected as the candidate low CTE alloy for development based on material performance, alloy maturity, and cost. Thermal expansivity is intermediate between Incology $903 / 909$ and typical disk alloys.

The ATS-S turbine nozzle case was selected as the component upon which to demonstrate Haynes alloy 242. A preliminary design of the case was completed, with thermal and stress analysis to follow. The turbine nozzle case may benefit from the relatively low expansion and increased operating temperature capability afforded by Haynes 242 alloy. Design Engineering is closely involved in the material development program, which will ensure the technology is integrated effectively in the first engine.

Drawings of the ATS-S nozzle case were delivered to 5 potential forging vendors for preliminary cost estimates. The supplier list was narrowed to two, based on several rating factors including cost, 242 experience, lead time and corporate technology base. Visits were made with each vendor to discuss forge processing, alloy heat treatment, and component design for producibility. Each supplier had useful input to the design. A forging source selection for this component is required next.

The starting billet size for the nozzle case forging was determined to be 10 " given the finished part dimensions. This is an issue for Haynes International since past billet production has centered on 8.5"diameter. Haynes does not see this as a long term issue and has agreed to demonstrate production of the $10^{\prime \prime}$ material at its expense.

A specification for Haynes Alloy 242 was drafted by Solar and reviewed internally. The specification was delivered to Haynes International for comment. A final specification will be published incorporating all changes. 


\section{WBS 19450 - Low Cost Casting Technologies}

This task is a collaborative effort with Howmet Corporation to investigate emerging new casting techniques which could significantly reduce the cost and improve the quality of stainless steel and superalloy components for industrial turbines. Two initial processes will be evaluated; Permanent Mold Casting (PMC) and Spraycasting technologies. The PMC process is similar to injection molding in that a water cooled reusable steel die is used, resulting in higher casting rates and reduced cost. The spraycast technique is a gas atomized spray forming process, based on the OSPREY process, for direct one-step conversion of superalloys to semi-finished rings. The high rate (100 pound per minute) spraycast deposition could potentially result in a cost reduction by requiring fewer processing steps relative to conventional forged ring products. This task will tailor these processes to industrial turbine components such as compressor blades and inlet guide vanes using PMC stainless steel. Spraycasting has strong potential for producing turbine nozzle cases and/or combustor housings in superalloy materials. Process qualifications including heat treatment and mechanical property testing will also completed in this task.

The primary benefit is reduced cost and improved component quality. In addition to cost reduction, the spraycast process may shorten the component development cycle and reduce lead time of production parts relative to conventional ring products. Rapid prototyping of parts may be achievable with the spraycast method. The process can also produce rings in materials considered "unforgeable", thus expanding the selections of materials available to the designer for turbine components.

Program accomplishments to date include the following:

Spraycast Development: The component selected for spraycast development is the ATS-S turbine nozzle case. As described in WBS 19440, the alloy for this component is Haynes 242 . The approach will be to compare the spraycast process head-to-head with conventional forging of Haynes Alloy 242 in terms of product cost and material properties.

1200 pounds of Alloy 242 raw material was purchased from Haynes International and delivered to Howmet for spraycasting. All the required tooling and expendables were delivered on schedule.

One 600 pound ring was successfully spraycast in Haynes Alloy. Preliminary reports from Howmet indicate that target metal flow rates and deposition characteristics were achieved in the first try. HIP process parameters are being investigated, with metallographic analysis of as-sprayed and post-HIP material underway. A second 600 pound ring will be spraycast after completion of the analysis.

A small test matrix has been devised to determine if the spraycast Haynes Alloy 242 material has a similar response to heat treatment as wrought product forms. This is considered a low probability of success since cast Alloy 242 is not heat treatable. If spraycast material should respond appropriately, this could represent a major breakthrough. If it does not respond, the spraycast ring will be used as a pre-form for conventional ring rolling as originally planned.

Permanent Mold Casting: Two candidate components have been selected for development of Permanent Mold Casting. First, the ATS-S compressor variable guide vanes represent a very attractive candidate for PMC. The guide vanes are non-rotating and carry relatively low aerodynamic loads, therefore present relatively low risk in demonstrating PMC components. 
Second, compressor blades will be evaluated for PMC. Due to the relatively high stress and fatigue aspect of rotating hardware, the compressor blade application is higher risk. However, results from an initial investigation of gravity fed PMC performed in a Solar funded program indicates that the process holds promise for rotating components.

A new vacuum injection molding facility has been installed by Howmet in Whitehall, MI (non-ATS funding). The equipment has been debugged and initial casting trials using first zinc, then titanium have been completed. Howmet feels the facility is ready for casting development for stainless steels.

A request for quotation (RFQ) was delivered to Howmet for development of $\mathrm{PMC}$ for industrial gas turbine compressor components. Howmet will provide cost and a timeline for a two phase program; 1) Early screening tests of the injection molding process for comparison to the previous gravity fed PMC work, 2) Scale-up and prototype engine hardware demonstration for ATS-S.

\section{WBS 19460 - NDE/Life Prediction Methods}

This task will continue the development of life prediction methodologies and Non-Destructive Evaluation (NDE) techniques initiated in ATS Phase 2 with Southwest Research Institute. The goal will be to refine stress analysis methods for high temperature components and modelling of the creep-fatigue behavior of materials. The technologies will be developed and applied first to critical turbine disks, then expanded to other high temperature turbine and combustion components. New retirement criteria for critical parts such as turbine disks will be evaluated in light of the program findings.

The analysis and inspection tools developed in this project will be important in the design of ATS components which are operating in more demanding conditions than in the past. As design temperatures increase the ability to predict component life becomes more challenging. Current analysis methods generally do not take into consideration the interaction between creep and fatigue at elevated temperature. This could result in underprediction of component life, or in other cases overly conservative design philosophy since the actual failure mechanism is not well understood.

\section{WBS 19500 - Recuperator Materials Development}

This task will identify next-generation materials for the ATS Primary Surface Recuperator (PSR) with the following two engine program goals in mind: 1) Increase the ATS-S recuperator life $\left(1200^{\circ} \mathrm{F}\right.$ inlet) relative to the current 30,000 hour limit for 347 stainless steel. This will improve RAMD and reduce life cycle cost of power in the ATS Program. 2) Demonstrate a recuperator material system for $1300^{\circ} \mathrm{F}$ service to allow future turbine uprates/growth. This second goal has strong spin-off potential as Solar has several active inquiries about higher temperature recuperator applications, including high volume automotive. The program will address all aspects of a new recuperator material including creep strength, oxidation resistance, forming and welding processes, mill producibility, and perhaps most importantly product cost.

To maximize the ATS benefits, these goals must be achieved at a reasonable cost. The recuperator materials program will develop the tools to analyze and select cost effective high performance materials for this purpose, including critically needed oxidation and creep life predictions, and a useful cost model of the recuperated cycle. In the process, an improved understanding of our current 
standard material 347 will result.

Program accomplishments to date include the following:

Considering the complexities of the program goals, a multidisciplinary team was formed consisting of academic researchers, a stainless steel mill, and the end-user (Solar). The team members are: University of California at San Diego (UCSD), Oak Ridge National Lab (ORNL), Allegheny Ludlum Corporation, and Solar Turbines.

A subcontract was awarded to UCSD to perform isothermal and cyclic oxidation experiments and to characterize oxide growth and failure mechanisms for input to the oxidation life model. UCSD will participate in the evaluation of reactive element additions to stainless steels.

A CRADA was negotiated with ORNL for its involvement in the recuperator materials team. This effort will involve the optimization of the performance of existing alloys for PSRs. Under the agreement, ORNL and Solar may collaborate in identifying and bringing to market cost effective stainless steels for application in current and future ATS designs. The CRADA will provide a potential avenue to bring to market unique strengthening technologies for stainless steels in a very high rate production product. ORNL also has expertise in the area of oxidation life prediction of high temperature materials.

Participation of a stainless steel mill, such as Allegheny Ludlum, was considered essential to ensure that producibility and realistic product cost projections would be considered. Allegheny has a very strong technical staff in the area of stainless steels as well, and has agreed to participate without direct charge to the program.

Several oxidation studies are underway on 347 and 310 stainless steel as baselines, and on candidate materials. Several long-term oxidation tests, initiated by Solar with internal funding, are proceeding. The high time test on 347 SS is now in excess of 15,000 hours at 1200F, which will provide an critical assessment of the oxidation behavior of foil material, data which is not available anywhere in the open literature.

Gravimetric and metallographic analysis of several shorter term oxidation tests of 347 and 310 stainless steel are also underway, with the goal of providing necessary constants to the oxidation life model. Projections from this data confirm that $347 \mathrm{SS}$ will not be adequate to reach the program goals and suggest that a minimum chromium content of $20 \%$ will be required.

\section{WBS 19710 - Advanced Coatings}

The objective of this task is to develop and evaluate reliable and durable advanced coating systems to meet ATS engine requirements. Advanced coatings include thermal barrier coatings (TBCs), abrasive blade tips (ABTs), and thick ceramic abradable coatings (TCATs).

Thermal barrier coatings are expected to provide metal wall temperature reduction for turbine blades and nozzles as well as for the combustor wall. This could allow for a higher turbine inlet temperature or a reduction in the cooling air requirements. In addition, TBCs could provide a more uniform temperature distribution around the turbine airfoil, thus reducing the effects of hot air streaks and hot spots. 
Abrasive blade tips and thick ceramic abradable coatings (ABT/TCAT) together form a system which is capable of maintaining a tight air seal between the rotating turbine blades and the shrouds. Higher engine efficiencies could be attained with the successful utilization of an ABT/TCAT system.

This task is devisable into the following subtasks, as described further below: (i) system evaluation; (ii) screening tests; (iii) Mars field tests; (iv) materials property measurements; (v) life predictions.

Program accomplishments to date include the following:

(1.) System Evaluation: This subtask has been completed.

Thermal Barrier Coatings (TBC): State-of-the-art and new TBC systems were identified as potential candidates for the ATS engine. The SOA TBCs included both air plasma sprayed (APS) and electron beam physical vapor deposited (EB-PVD) yttria stabilized zirconia (YSZ) ceramic top coatings, and plasma sprayed and platinum diffusion aluminide (Pt-Al) bond coatings. The new TBC systems present a potential to provide an improvement to the state-of-the-art TBC systems. These systems are:

- $\quad$ Air plasma sprayed 7-8 wt.\% YSZ ceramic top coat over pack diffusion platinum aluminide bond coat

- $\quad$ Slurry sprayed $\mathrm{Al}_{2} \mathrm{O}_{3} / \mathrm{SiO}_{2}$ ceramic coating

- $\quad$ Air plasma sprayed 7-8 wt.\% $\mathrm{BaZrO}_{2}$ YSZ ceramic top coat over a low pressure plasma spray CoNiCrAlY bond coat.

- $\quad$ Air plasma sprayed 7-8 wt.\% YSZ ceramic top coat over electro-spark discharge diffusion platinum aluminide bond coat

Procurement of coated specimens and plasma spray powders for the in-house thermal spray development was completed. This included the following powders:

- $\quad 7-8 \mathrm{wt} . \% \mathrm{Y}_{2} \mathrm{O}_{3}$ stabilized $\mathrm{ZrO}_{2}$ manufactured by the sol gel process.

- 7-8 wt. \% $\mathrm{Y}_{2} \mathrm{O}_{3}$ stabilized $\mathrm{ZrO}_{2}$ manufactured by the HOSP process.

- $\quad$ 7-8 wt. \% $\mathrm{Y}_{2} \mathrm{O}_{3}$ stabilized $\mathrm{ZrO}_{2}$ manufactured by the agglomerated and sintered process.

- Low sulfur CoNiCrAlY +Si powder.

All powders were received, sprayed and evaluated except the sol gel material. Processing problems were the main reason for this delay. No availability date was given by the supplier.

In-house thermal spray TBC development activities were started during this period. Eight sets of MAR-M247 nickel superalloy specimens were sprayed with various TBC systems. TBC system variables included:

- Two metallic bond coat materials: 6 wt.\% Al-NiCrAlY and 12 wt.\% Al-CoNiCrAIYSi.

- Low sulfur, 12wt.\% Al-CoNiCrAlY bond coat material

- Two ceramic top coat materials: $\mathrm{CaTiO}_{3}$ and 8 wt. $\% \mathrm{Y}_{2} \mathrm{O}_{3}$ stabilized $\mathrm{ZrO}_{2}$. 
- $\quad$ Four 8 wt. $\% \mathrm{Y}_{2} \mathrm{O}_{3}$ stabilized $\mathrm{ZrO}_{2}$ powders:

i) $\quad \mathrm{Z}-1087$ powder supplied by Cerac

ii) Metco 204 powder supplied by Metco Seltzer

iii) AE-7512 powder supplied by Metco Seltzer

iv) ZRO-196 powder supplied by Praxair

Metallographic evaluation of the as-coated specimens was completed. All coated specimens exhibited uniform coating appearance with no evidence of coating spallation or cracking. Porosity levels in the ceramic top coating ranged between 10 and 40 area\%. Parameter development was conducted to optimize coating porosity levels.

Room temperature bond strength tests per ASTM C-633 were conducted on the coated specimens. Coatings with lower porosity levels exhibited bond strength values that ranged between 2140 and 3640 psi using fine grain YSZ. Coatings with higher porosity levels and coarser YSZ grains exhibited bond strength values that ranged between 1100 and 1440 psi. It was evident that the bond strength of the TBC systems was inversely related to the ceramic coating porosity levels and the YSZ grain size. All bond strength failures were at the metallic bond coat/ceramic top coat interface.

Metallurgical evaluation of three TBC systems that were supplied by outside suppliers, was conducted. The three TBC systems were:

- $\quad \mathrm{SiO}_{2} / \mathrm{Al}_{2} \mathrm{O}_{3}$ spray-and-cure ceramic coating

- Low pressure plasma spray CoNiCrAlY bond coat with a $\mathrm{BaZrO}_{2}$ ceramic top coat

- $\quad$ Platinum aluminide bond coat with a plasma spray $8 \mathrm{wt} \% \% \mathrm{Y}_{2} \mathrm{O}_{3}$ stabilized $\mathrm{ZrO}_{2}$ top coat.

In-house thermal spray TBC development activities were conducted to develop optimum spray parameters for the bond and top coatings. Optimum spray parameters for the metallic CoNiCrAlYSi and the ceramic Metco 204 yttria stabilized zirconia powders were reached. Coarser CoNiCrAlYSi powder was used to obtain rougher bond coating surface, and higher power plasma flame was used to spray the Metco 204 powder (coarse powder size) in order to achieve denser (10-20\% porosity instead of $40 \%$ porosity) ceramic top coating. The bond strength of the optimized plasma sprayed TBC was measured at an average of 2200 psi. Initial powder properties such as size distribution, density and chemical composition were determined. This information was needed to establish materials' "as-received" conditions.

An eddy current, non-destructive evaluation, device which is capable of measuring coating thickness was purchased.

Abrasive Blade Tips (ABT): Three ABT systems were selected for the ATS program - two commercially available systems and one in-house developed system. The commercial systems are: The Liburdi powder metallurgy (PM) tape, and the Praxair/BAJ electroplate process. The Solar developed process is designated as Controlled Composition Reaction Sintering (CCRS). This process involves the spraying of $\mathrm{Al}_{2} \mathrm{O}_{3}$ particles in an aqueous solution followed by pack cementation aluminizing. This process was developed in 1991 and was proven to provide adequate wear characteristics. 
System evaluation criteria were defined in this task. These included $\mathrm{ABT}$ microstructure, composition, thickness, microhardness, bond strength, thermal stability, thermal shock, rub characteristics, and ease of manufacturability.

Thick Ceramic Abradable Coatings (TCAT): Three TCAT systems were selected for the ATS program. These include one commercially available plasma spray system from Pratt \& Whitney Talon, one in-house functionally graded plasma spray system, and one system which is still under development by an outside source (Dytech). The latter system is a monolithic porous ceramic overlay attached to a metallic shroud.

System evaluation criteria were defined in this task. These included TCAT microstructure, composition, thickness, microhardness, bond strength, thermal stability, thermal shock, rub characteristics, and ease of manufacturability.

\section{(ii.) Screening Tests}

Thermal Barrier Coatings (TBC) - A cyclic oxidation test at $2000^{\circ} \mathrm{F} / 1000$ hours (100-hour cycles) was conducted on the coated specimens. Two specimens that were coated with the $6 \mathrm{wt}$.\% Al-NiCrAlY bond coat and $\mathrm{CaTiO}_{3}$ and YSZ ceramic top coats spalled after 4 cycles. The $\mathrm{SiO}_{2} / \mathrm{Al}_{2} \mathrm{O}_{3}$ spray-and-cure ceramic coating and the low pressure plasma spray CoNiCrAlY bond coat with a $\mathrm{BaZrO}_{2}$ ceramic top coat failed after 3 cycles. All other specimens that were coated with 12 wt.\% Al-CoNiCrAlY bond coat, survived the test with no evidence of coating spallation or cracking. Metallurgical evaluation of the oxidized specimens was conducted.

Chemical examination of the oxide scales formed along the bond/top coatings interface was conducted using a scanning electron microscope equipped with an energy dispersive $\mathrm{x}$-ray analyzer. Analysis was conducted on two systems: NiCrAlY/CaTiO3 and CoNiCrAlYSi/YSZ. The former failed after 4 cycles and the latter survived the ten cycles. Further chemical examination and evaluation of the systems is underway to better understand the failure mechanisms of TBCs.

In general, yttria stabilized zirconia TBCs outperformed the calcium titanate in this test regime. In addition, 12 wt. \% Al CoNiCrAlYSi bond coating outperformed the 6 wt.\% Al NiCrAlY. Ceramic coating densification was also observed after the oxidation exposure.

Further screening tests of the EB-PVD and improved plasma sprayed TBCs was conduced during a second round of cyclic oxidation testing. The TBC systems tested were:

- $\quad$ LPPS CoNiCrAIYSi/EB-PVD YSZ (Chromalloy and Supplier X)

- Pt-Al/EB-PVD YSZ (Chromalloy and Howmet)

- $\quad$ Argon shroud CoNiCrAlYSi/Argon shroud YSZ (Praxair)

- $\quad$ HVOF CoNiCrAIYSi/plasma spray YSZ (Sermatech)

- $\quad$ Plasma spray CoNiCrAlYSi/plasma spray YSZ (Solar)

- $\quad$ Plasma spray low sulfur CoNiCrAlYSi/plasma spray YSZ (Solar) 
Table 1 summarizes the results of the screening test.

Table 1

\begin{tabular}{|l|l||}
\hline TBC System & Cycles to Failure \\
\hline LPPS CoNiCrAlYSi/EB-PVD YSZ (Supplier X) & 1 \\
\hline LPPS CoNiCrAlYSi/EB-PVD YSZ (Chromalloy) & 3 \\
\hline Pt-Al/EB-PVD YSZ (Chromalloy) & 9 \\
\hline Pt-Al/EB-PVD YSZ (Howmet) & +12 (continuing) \\
\hline Ar shroud CoNiCrAlYSi/Ar shroud YSZ (Praxair) & 3 \\
\hline HVOF CoNiCrAIYSi/APS YSZ (Sermatech) & +12 (continuing) \\
\hline APS CoNiCrAlYSi/APS YSZ (Solar) & +12 (continuing) \\
\hline APS low S CoNiCrAlYSi/APS YSZ (Solar) & +12 (continuing) \\
\hline
\end{tabular}

Metallurgical evaluation of the failed TBCs is in progress.

\section{(iii.) Mars Field Test}

Selection of state-of-the-art TBC systems for the Mars production engine test was completed. The selection was based on the availability and experience that coating suppliers and other gas turbine manufacturers possess at the time. Selected coating systems are:

- $\quad$ Air plasma sprayed 7-8 wt.\% YSZ ceramic top coat over a low pressure plasma spray CoNiCrAlY + Si bond coat.

- $\quad$ Argon shroud plasma sprayed 7-8 wt.\% YSZ ceramic top coat over argon shroud plasma spray CoNiCrAlY + Si bond coat.

- $\quad$ Electron beam physical vapor deposited 7-8 wt.\% YSZ ceramic top coat over low pressure plasma sprayed CoNiCrAlY + Si bond coat

- $\quad$ Electron beam physical vapor deposited 7-8 wt.\% YSZ ceramic top coat over precious metal diffusion aluminide bond coat

The preceding systems were applied on turbine blades and nozzles as well as on a combustor transition piece for a rainbow engine test. Equiaxed (Mar-M247) and single crystal (CMSX-4) nickel based superalloy blades were selected for a possibly two engine tests; a Mars 90 with a firing temperature of $1935^{\circ} \mathrm{F}$ and a Mars 100 with a firing temperature of $2050^{\circ} \mathrm{F}$.

Full metallurgical evaluation was conducted on the various TBC systems. Evaluation included: microstructure, composition, thickness profiles, and surface finish measurements. This data was useful in establishing TBC baseline for further improvements and was used for initial aero and heat transfer designs on the ATS components.

Three TBC systems applied on a Mar-M247 turbine blades (Mars 90 bill-of-material blades) were assembled in a Mars 90 engine for field evaluation. Eight blades were coated with each TBC 
system. The blades were distributed with standard platinum aluminide coated blades in the stage 1 turbine disk. The field unit is expected to start running in November 1996. Boroscope inspection of the blades is planned.

The three TBC systems were:

- $\quad$ LPPS CoNiCrAIYSi/EB-PVD YSZ supplied by Supplier X

- $\quad$ LPPS CoNiCrAIYSi/EB-PVD YSZ supplied by Chromalloy NY

- $\quad$ Pt-Al/EB-PVD YSZ supplied by Chromalloy NY

The remaining CMSX-4 TBC coated blades, nozzles, and the sliding ring are awaiting an available engine for field testing.

\section{(iv.) Materials Property Measurements}

A meeting was held with Caterpillar Technical Center to discuss the program needs for materials property data measurements. Discussions were conducted to establish the required data to support heat transfer and mechanical designs as well as the life prediction modeling for the ATS components.

A visit to Caterpillar Technical Center was conducted where a matrix of material property measurements was formulated. Specimens procurement and preparation is in progress.

\section{(v.) Life Prediction}

Discussions were conducted with Southwest Research Institute (SWRD) to implement their life prediction model which is under development under the DOE ATS/TBC program with Westinghouse on Solar TBC system and ATS turbine components. A preliminary proposal was submitted by SWRI and a list of thermophysical and mechanical requirements was established. A kick-off meeting was scheduled in October for final definition.

\section{WBS 19720 - CVD Internal Coatings}

The objective of this task is to evaluate the uniformity and reproducibility of chemical vapor deposited (CVD) gas phase aluminide coatings inside the cooling passages of ATS turbine airfoils. Aluminide coatings provide oxidation and hot corrosion protection during service to metal surfaces. A high temperature recuperated air will be used in the S-engine for cooling the turbine blades and nozzles. At this temperature, partial oxidation and hot corrosion attack could occur inside the cooling passages of the airfoils. The chemical vapor deposition (CVD) process has been used to coat the internal passages of aircraft engine components with aluminide coatings. These coatings are similarly expected to provide protection to the internal surfaces of the ATS blades and nozzles, thus increasing their service lives. ,

Program accomplishments to date include the following:

Ten production Centaur 50 stage 1 turbine blades were sent to two coating suppliers (Howmet and Chromalloy) for process evaluation. One set (5 blades) from Howmet was received and evaluation is in progress. 
Air flow measurements were conducted prior to and after coating the internal passages of the blades. A flow reduction of $2.5-4.5 \%$ was measured after internal coating; nevertheless, all blades met design flow requirements. One blade from this set is being sectioned for metallurgical evaluation of the internal coating thickness uniformity.

\section{WBS 19730 - Alloy/Castings System}

The objective of this task is to evaluate the coatability of low sulfur and rare earth element modified alloys used for ATS engine components. New alloys such as CMSX-10 and CMSX-11 are being evaluated in the ATS program. These alloys require protective coatings for an increased service life. Limited experience is available on the coatability of these alloys. Precious metal modified aluminide coatings on CMSX-10 and CMSX-11 alloys are expected to provide the oxidation and hot corrosion protection to meet ATS engine life requirements.

Program Accomplishments to date include:

Three low sulfur, rare earth element modified CMSX-4 alloy samples and CMSX-10 samples were procured. The sample geometry was $0.75-1.25^{\prime \prime}$ diameter $\times 5^{\prime \prime}$ long rods that were cast by Cannon Muskegen, Whitehall, MI. The chemistries of the three modified CMSX-4 specimens are:

- $\quad$ CMSX-4 + 36-59 ppm lanthanum (La)

- $\quad$ CMSX-4 + 40-68 ppm cerium (Ce)

- $\quad$ CMSX-4 + 14-22 ppm Lanthanum (La) + 11-19 ppm yttrium (Y)

All three alloys are designated as ultra low sulfur (ULS), i.e., $<1 \mathrm{ppm}$ S.

Sample preparation is underway. $0.75^{\prime \prime}-1$ " diameter $\times 0.125^{\prime \prime}$ thick buttons are being prepared by EDM sectioning.

Two coating suppliers, Chromalloy and Howmet were identified with capabilities and expertise for coating these alloys. A non-disclosure agreement with Chromalloy has been drafted.

\section{WBS 19800: Advanced Diffusers}

The concepts being investigated under this task, while generic in nature, will be initially targeted to improving turbine exhaust diffuser static pressure recovery $(\mathrm{Cp})$. Improved pressure recovery at the turbine discharge results in reduced back pressure, which translates to higher turbine power output and efficiency. Annular diffusers are used in gas turbines at the discharge of the compressor and turbine. In a shaft power application, engine performance is more sensitive to diffuser pressure recovery at the turbine discharge location. Not only is the velocity head leaving the turbine usually greater than that leaving the compressor, but also a portion of the velocity head leaving the compressor diffuser is recovered in the combustor, while any head leaving the turbine diffuser is lost to the atmosphere.

Diffuser pressure recovery is sensitive to several parameters related to the geometry and inlet flow conditions. Geometrically, the most important parameters are the non-dimensional length to inlet 
height ratio and the exit to inlet area ratio. Aerodynamically, the most important parameter influencing the diffuser pressure recovery is the inlet boundary layer blockage, which on this rig is being varied with different lengths of constant annulus area ducts upstream of the diffuser model.

Program accomplishments to date include the following:

All testing to date has been conducted at a non-dimensional length of 10 . The area ratio was varied by modifying the diffuser outer wall divergence angle. The inner wall angle was also varied; however, the configuration most closely modeling Solar's typical exhaust diffuser configurations was used for the bulk of the testing. Testing was also conducted with and without eight airfoil shaped struts, to assess the impact of these typical bearing support features on diffuser performance. These struts were tested in three different configurations: axially oriented with no airflow incidence, and rotated to simulate 10 and 20 degrees of incidence.

Testing was initially conducted on the different geometry configurations to obtain 'clean' diffuser performance (i.e., no vortex generators or struts). The 10 degree outer wall exhibited the highest clean pressure recovery, but through the use of vortex generators (VG's) to energize the boundary layer, the highest recovery was achieved using the 11 degree outer wall; therefore, this geometry was selected as the baseline for further investigations.

Using VG's, the pressure recovery is improved $12 \%$ on the clean geometry, and only $6 \%$ on the configuration with struts. The reduced improvement with struts is attributed to vortices which are generated by the struts themselves causing some improvement in recovery. This would also explain the slight improvement in recovery when comparing the strut only configuration to the clean baseline. The improvement in recovery due to VG's is valid with up to 10 degrees of incidence on the struts. Testing conducted at 20 degrees of strut incidence showed severe flow separation and reduced pressure recovery. The use of VG's in this configuration showed no improvement in recovery.

\section{WBS 19900 - Advanced Man Machine Interface (MMI)}

The objective of this task is to develop an advanced MMI with integrated electronic documentation, expert systems and user configurable reports and communication options. The advanced MMI will improve the utilization of turbomachinery resources by providing timely and succinct feedback to the operations personnel to enhance their decision making process. Advanced communications will enable the equipment control and monitoring to be performed locally or remotely. Expert knowledge, drawings and electronic documentation will be embedded in the operator interface. The program objective of improving the reliability, availability, maintainability and durability (RAMD) of the ATS system will also be furthered as this task will include the development of a data acquisition system that will download information to the RAMD system being developed by Fluor Daniel under WBS 65000.

Work on the MIII commenced in Phase 2 involving preliminary design of the system and investigation into enabling technologies, including graphics environments, communications technology and operating systems. (See Phase 2 Topical Report 8.6.) Work continued under Phase 3 starting in April, 1996. 
Program accomplishments to date include the following:

The initial design of a 32 bit alarm subsystem configuration program has been completed, as has the design and development of a 32 bit Allen Bradley driver. An extension of the alarm subsystem will collect data for the RAMD system. As a predefined event occurs (e.g., shutdown), the alarm subsystem will detect it and prompt the operator to classify the event (planned / unplanned), identify the subsystem which caused the event and record which part(s) was replaced to correct the problem. Since some of this information will not be known at the time of the event, the alarm subsystem will periodically repeat the prompt until the missing information is entered.

Other work during the period included an in depth review of OLE for Process Control (OPC) standards and an initial determination regarding how to implement selected MMI software components in a manner that is OPC compliant.

Initial data analysis was performed for the expert system. Diagnostics and predictive trending will be implemented as MMI subsystems. Diagnostic routines will consist of pre-developed Visual Basic programs that will utilized current and historical data as well as logic to provide information and recommendations to the operator.

A proposal from a system developer (DAZSI) has been received and is under review for the completion of the overall MMI system architecture and component design.

The effort required under this task will be greater than originally estimated, in particular due to the inclusion in the task of the development of the data acquisition system for the RAMD system. This should be offset by a reduction in the effort required under WBS 65000 . Also the efforts to support the integrated expert system are higher than anticipated. The initial version of the MMII should be completed by June, 1997; the data analysis for the expert system should be completed by May, 1998.

\subsection{Engine and Package}

\section{WBS 20200 - Engine Definition}

Due to funding limitations, work on the $\mathrm{L}$ has been largely limited to concept design. Concept and configuration refinements were presented to DOE during the quarterly review held in May, 1996. DOE comments and suggestions have provided the basis for further studies and refinement.

\subsection{Test and Evaluation}

\section{WBS 42100 - Compressor Test Rig}

A compressor test rig is required to verify S-engine compressor aerodynamic prediction and L-engine compressor direct scaling prior to design release and engine test. The full scale compressor test rig serves to evaluate, validate, and recommend improvements to the analytically predicted aerodynamic performance parameters of the ATS axial flow compressor using appropriate instrumentation to measure, record, and monitor specific parameters (including efficiency as a function of speed, flow parameter, pressure ratio, and development of the compressor map) in a representative compressor configuration. 
After evaluating several subcontractors to design/fabricate/instrument/assemble a compressor rig, Agilis Group, Inc. was selected based on technical capability, supplier base, cost, and priority/schedule demands. The purchase order for rig design was awarded to Agilis in October, 1995. With Solar supplied airfoils (fabricated blades and variable vanes by PCI of BTI, Inc.) Agilis will design the remainder of the rig based on Solar's configurational requirements, design criteria, and instrumentation requirements. The design uses computer aided design (CAD) models coordinated by compatible software formatted in Pro/E. The structural and thermal analyses use a 3-D finite element analysis program (ANSYS) that has effective interfaces with Pro/E.

After evaluating several subcontractors for test facilities and testing capabilities of the compressor aerodynamic rig, WPAFB/CRF was selected based on technical capability, facilities/equipment, experience, cost, and schedule requirements. The purchase order for rig testing was awarded to WPAFB/CRF in November, although the CRADA was not finalized until April, 1996.

A compressor rig Preliminary Design Review was held at Solar in December, 1995. The design criteria, bill of materials for rig configuration, rotor structural and dynamic analyses, rig/facilities interfacing, and instrumentation list were covered at the review. A critical design review followed at Agilis' facilities in February, 1996, with concurrence obtained on component design and analyses (inlet housing, \#1 bearing compartment, rotor disks/blades, compressor case, variable vanes, blade tip clearances, thrust balance, \#2 bearing assembly, aft support), test facility integration, and instrumentation.

Definition of the compressor airfoils was completed in April to a level sufficient to support concurrent hardware manufacture drawings were released 4 months later. Rig design was completed in March, and component designs were released for fabrication. All hardware is anticipated to be fabricated or procured by the end of October.

A test readiness review was held at WPAFB/CRF in August. The test plan outline was reviewed in detail; facilities and hardware integration were verified with the installation sequencing procedure, the hardware status list, and the facility requirements worksheets; instrumentation list were updated, and DA.S was coordinated. The test plan is anticipated to be completed this November.

\section{WBS 42210 - Ultra-Lean Premix Combustor Test Rig}

A full annular test rig is being designed, fabricated, instrumented, and assembled for testing designs of the S-engine ULP combustion system prior to design release of the first S-engine. The rig is a critical element in the plan to develop the combustor liner and fuel injection system with variable geometry flow for the low emissions combustion system. The rig will incorporate results of technology development efforts under WBS 19210 and WBS 19230.

A resource plan for rig design layout is in process, and the design of the test rig is scheduled to continue through the remainder of calendar 1996.

\section{WBS 42400 - Turbine Test Rig}

A turbine test rig is required to verify the S-engine turbine aerodynamic predictions prior to design release and engine test. This "cold" uncooled aerodynamic turbine rig is intended to evaluate, 
validate, and provide direction for potential improvements to the aerodynamic performance. The half scale, two stage turbine rig is to be capable of providing stage as well as overall performance data using appropriate instrumentation. Off-design mapping of the turbine will also be included in the test plan.

The design, fabrication, instrumentation, and assembly of the test article was subcontracted to Caterpillar Technical Center in June, 1996. Test article concept design is nearing completion. The completed airfoil definition is being reiterated with mechanical design requirements. The inlet and exhaust collector aero definition is in process, including vortex generator diffuser mapping. The rotor system dynamic analyses are also being reiterated. A design review is scheduled for the end of October.

Testing will also occur at Caterpillar Technical Center. Conditioning and modification of the test facility for test article has commenced and should be completed in December. This will require test cell drive system updating, instrumentation, and miscellaneous ducting. Tech Center is currently in the process of analyzing a drive system with Westech gearbox, eddy-current dyno, drive coupling, and phase displacement torque meter. The inlet plenum with tie rods for high pressure ratio testing is incorporating heated inlet air ducting to produce rig exit temperatures near ambient and well above freezing temperature.

Instrumentation design is ongoing. Instrumentation requirements are being designed into both the test article and the test facilities.

The Tech Center is on schedule to complete test rig design by January, 1997. Rig hardware will be fabricated during the first quarter of 1997 with rig build scheduled for completion in May.

\section{WBS 42500 - Squeeze Film Damper Test Rig}

The "S" engine will utilize anti-friction bearings in order to reduce the oil flow and, therefore, the size and cost of the sumps, pump and cooler. These bearings require squeeze film damping to satisfy the rotor dynamics. A test rig is being designed, fabricated, instrumented, and assembled for testing designs of the S-engine squeeze film damper system prior to design release for manufacturing and engine test. The rig will allow Solar to verify analytically predicted damping coefficients as a function of rotating speed, oil film supply pressure, and bearing configuration for squeeze film damper designs of rolling element bearing systems.

The rig design layout has been completed with specifications for the oil system, hydo-mechanical shaker, load cells, and data acquisition system. We are on schedule to have the rig build completed during the first quarter of 1997.

\subsection{Other}

\section{WBS 65000 - Reliability, Availability, Maintainability and Durability (RAMD)}

One of the principal objectives of the ATS Program is to maintain or improve the RAMD of the ATS relative to the best systems currently available. The RAMD parameters of the power or industrial plant, in turn, significantly affect the life cycle cost of the plant. Parameters of plant and component reliability, plant availability, plant and component maintenance costs, and performance retention of 
the ATS plant should be monitored to evaluate the life cycle costs of the industrial power plant. RAMD analysis and on-line monitoring will help the plant owner to evaluate the engine and track the operating and maintenance parameters of the Advanced Turbine System and verify its overall life cycle cost of the plant.

This task covers the generation of a RAMD database for the ATS systems and the development of an integrated RAMD system that will continually download actual information from the operating plant for RAMD analysis. Improvement in the RAMD parameters will be achieved by first downloading the operating parameters of the ATS plant and then tracking the RAMD parameters throughout the demonstration phases and subsequent deployment of the industrial fleet. RAMD parameters will be analyzed on a continuing basis enabling improved design features (if required) to increase the RAMD of the ATS plant.

Solar is working closely with its subcontractor Fluor Daniel on the task. The purchase order for Fluor Daniel was released in January, 1996. A specification for the RAMD methodology was completed in May, including a conceptual definition as well as the development of terms and formulae for the system.

During mid-1996 Solar and Fluor Daniel have held coordination meetings aimed at minimizing the overlap between Fluor Daniel and Solar's Controls group. As a result, Solar will retain responsibility for the development of the data acquisition system as part of the advanced MMT being developed under WBS task 19900, while Fluor Daniel is designs the on-line RAMD performance and monitoring system, which will analyze the information downloaded from the DAS.

Design and development of the on-line RAMD and performance monitoring system will continue throughout 1997 with hardware and software to be procured, installed and tested on the first $S$ inhouse test engine. The system is thus expected to be operational to gather and analyze RAMD information on the host site demonstration systems.

\subsection{COMMERCIALIZATION}

The following activities undertaken during the year since contract award directly further the commercialization potential of the ATS products.

\section{WBS 52400 - Market Coordination}

The Market Requirement Specification for the ATS-S was developed in the first quarter of 1996. This formed the basis for the Product Requirement Specification, which was approved in April. A preliminary Market Requirement Specification has also been developed for the ATS-L but is undergoing further refinement.

A presentation was made to the Gas Research Institute's power generation advisory group in February regarding ATS technologies and the key role that it can play for the gas industry. The attendees agreed that distributed generation will play an important part in GRI's overall strategy, and ATS was identified as a technology of choice.

Solar met in Washington DC in March with DOE's Director of Technology Development and three program managers for DOEs "vision industries." The meeting addressed the commercialization of 
ATS and the benefits that can be realized by coordinating ATS with DOE's ongoing efforts with the seven vision industries. In May Solar made a presentation to OIT's program Managers for the vision industries and representatives of the industries. Ongoing work will be continued to further this strategic opportunity for such cross-cutting technologies as ATS.

Solar was a Steering Committee member for the California Energy Commission's workshop on distributed generation held in April. The workshop was well attended by a broad spectrum including public agencies, legislative staff members, technology companies, industry and financial institutions. CEC Chairman Embrecht provided the keynote outlining a vision for distributed generation. The ensuing workshop focused upon impediments to siting, possible solutions and necessary actions. A report and action plan will be forthcoming in the upcoming reporting period.

Solar has made several presentations during the reporting period regarding the Solar's ATS products and the emerging distributed generation application. These include the following:

- A paper and presentation in March to the American Public Power Association regarding distributed power generation and the role of advanced industrial gas turbines,

- Attendance of a conference in February sponsored by Infocast regarding municipalization in the electric power industry,

- Attendance of a conference in March sponsored by EPRI and NREL regarding the integration of renewable energy technologies and advanced gas turbines.

- Tenth annual Spring Regional Conference, sponsored by the Gulf Coast Power Association. The conference was attended by companies interested in small on-site power generation and co-generation. Solar's presentation and paper discussed the company's ATS products and the role they will play in distributed generation.

- DOE Export Trade Assistance office. Solar reported on trends in developing countries that will favor modular generation and discussed how the ATS products will be able to competitively meet those needs.

- Distributed Utility workshop, sponsored by the Gas Research Institute. The workshop was attended by representatives of public agencies, utilities, and industrial concerns.

- Third annual Advanced Combustion Turbines Conference, sponsored by Energy Daily. The presentation focused upon transportable power and its application in distributed generation.

Solar has also held a number of meetings with various stakeholders regarding potential applications of ATS products and technologies. Among those meetings were:

- Electric Power Research Institute (EPRD). Solar discussed the economics and siting characteristics of distributed generation and sought information regarding ongoing EPRI work relevant to distributed generation. Solar and EPRI will have continuing communications on the subject, and EPRI will be consulted regarding potential distributed generation test activities. Solar will be addressing the attendees of EPRI's distributed 
resources week long conference in November, 1996.

A graphic image representing the collaboration between Solar and DOE on the ATS program was developed in early 1996 and has been used both for internal communications and in presentations to agencies and potential customers.

Solar has also hosted numerous guests at our facilities, including representatives of local, state and federal government agencies. These visits have provided Solar the opportunity to inform and advise the agencies regarding emerging technologies and applications, as well as Solar's progress and commitment to the ATS program. Visitors during this period have included California governor Pete Wilson, DOE Deputy Secretary Christine Irvin, senior Congressional staff member Loretta Beaumont, Congressman Brian Bilbray, California Energy Commissioners Dr. David Rohy and Vicechair Sally Rakow. Solar has also hosted industry institutions such as GRI and EPRI. GRI held its Power Generation Project Advisory Group meeting in February, 1996 in San Diego at which Solar provided a presentation on ATS and sat in on a panel discussion regarding emerging technologies.

As discussed further under the Program Management discussion (section 5.1), Solar has sought outside funding for ATS related activities including market related efforts. The California Matching Fund contract that was finalized in September, 1996 includes funding that will be used to contract a study regarding the regulatory and institutional barriers of siting distributed generation and the ATS technologies in particular. This information will be used as part of the commercialization plan that will be submitted to DOE under WBS 61000.

The Marketing group is also coordinating closely on an ongoing basis with Solar's Customer Services and Project Finance groups to ensure that total lifecycle cost management is a prime consideration as we take the ATS product to market.

\section{WBS 52500 - Product Cost Management}

An introductory Design to Cost workshop was held in January 1996 with fifty participants representing mechanical design, manufacturing engineering and purchasing. The session met the objective of raising awareness of manufacturing cost drivers so that cost can be designed out of the product during the concept development phase. Feedback from participants was extremely favorable and follow up sessions will be held as the design takes shape.

Models were developed from historical data on existing Solar products to assist in establishing cost targets for the S-engine and package. Accountability for the resulting targets has been accepted by the NPI team and published in the product specification. Frequent clarification meetings are held with marketing to ensure that the product cost and features are aligned with market expectations. Life cycle cost considerations and service contracts are also being evaluated.

The S-engine manufacturing kickoff was held on June 7, 1996 and Manufacturing Producibility Reviews were conducted the week of June 17, 1996. Seven, three hour long working sessions, facilitated by Solar's consultant MRI, were held with very constructive discussion among nearly 100 participants from design, aero, layout, manufacturing, and purchasing. The sessions also served as a kickoff for the involvement of Solar's Turbomachinery Operations (TMO) Certified Assembly and Manufacturing units (CAMs). Action items were assigned to the design leads and manufacturing 
focal points. The reviews will form the basis of Manufacturing Design guides intended to incorporate lessons learned from current and previous product development efforts to ensure that cost and producibility goals are met.

A field service session was hosted at Solar's overhaul facilities in DeSoto, Texas in September, 1996. The program was presented by the lead design engineers for each primary section of the engine and the manufacturing team leader. The TMO team received several good ideas for consideration in the design. Dramatic cost reduction ideas affecting the Combustor and Turbine sections of the engine are being investigated.

\section{WBS 61000 - Market Strategy \& Readiness Plan}

In early 1996 Solar proposed that the commercialization plan be delivered in March of 1997 consistent with the recognition that the dynamic marketplace will drive product placement strategies. DOE acknowledged the requested schedule change. Solar is on schedule to meet this deliverable.

The commercialization team was ratified by Solar's President's staff members with the charter of developing the commercialization plan and to specifically address options pertaining to the distribution of the ATS product. The team consists of members from Marketing, Sales, Application Engineering, Project Management, Construction Services, and Customer Services. The results of the committee's findings will be included in the plan.

On-Site Energy has been assigned the responsibility of preparing the draft plan, in coordination with the ATS Marketing Manager. The outline has been developed, and several sections are currently being drafted including an update of the energy needs of DOE's "Industries of the Future" and the ability of the ATS products to meet these needs.

Solar collaborated with the Interstate Natural Gas Association of America (INGAA) in the preparation of its study regarding distributed generation and the opportunities presented for the gas industry. The report, which was delivered in May and was well received by the gas industry, included discussion regarding advanced technologies such as Solar's ATS products. As a result of the acceptance of this report, INGAA will be forming the Distributed Power Coalition of America. Solar will continue to play an active role in supporting these efforts.

Fluor Daniel and Solar prepared a questionnaire that was sent in August to over 100 customers of Fluor Daniel worldwide. The responses to the questionnaire will be useful in independently validating Solar's global market data for efficient small power generation systems and in obtaining market information for a broader potential customer base for ATS. Additionally the information will be used by Fluor Daniel in calibrating its independent commercialization plan for the placement of Solar's ATS products. Over 40 responses have been received to date - many of which requested further information regarding the Solar's ATS products and their availability.

\section{WBS 71000 - Host Site}

Solar has entertained discussions with a number of interested entities regarding the location of a host site for the 8,000 hour field demonstration of the ATS system. Solar's approach is to identify and develop and agreement with a host utility, which can assist in the location of one or more industrial 
host sites to be selected by Solar, DOE and the host utility. Interested utilities have included investor owned utilities as well as municipal utilities. Selection and preliminary agreement with a host utility is anticipated to occur in the first quarter of 1997.

\subsection{PROGRAM MANAGEMENT}

\subsection{Program Management Activities}

Startup Activities: In the months immediately following the award of the cooperative agreement in September, 1995 a number of activities were undertaken.

- Solar established its Payment Management System consistent with the cooperative agreement provisions and commenced direct draws against the DHS account. Allowable preaward costs were consolidated and drawn. Backup was submitted to DOE.

- A petition for advance patent waiver was submitted.

- The list of Environmental, Safety and Health (ES\&H) approvals was submitted in accordance with the cooperative agreement requrements.

- Solar's and DOE's contract specialists coordinated guidelines for notification and approval of subcontractors and material suppliers. A cooperative agreement amendment was generated in January, 1996 incorporating this agreement.

- A new rough-order-of-magnitude (ROM) quotation process and input form were implemented to encourage engineering to involve suppliers in the concept phase of design. The process allows suppliers to provide technical advice and rough production prices on design concepts without binding them to a firm sell price. This ROM process can be executed in a week or less compared to the four to six weeks typically required to solicit a formal quote.

Management Plan: A Preliminary Management Plan was prepared and submitted to DOE the first week in November, 1995. The Preliminary plan was based upon the program structure and schedule contained in Solar's proposal. However, it was anticipated that a revision would be required following completion of budget appropriations since the program schedule would need to be modified to fit DOE's available funding profile. A revised WBS Index, WBS Dictionary and schedule was provided to DOE at the first quarterly review, held in February, 1996.

At DOE's request a revised Management Plan was submitted in September, 1996. The Management Plan revision reflects the program/schedule modifications that have been required as a result of the substantial shortfall in available funding from originally approved contract amounts.

Reviews: Solar and DOE have held periodic reviews on a regular basis. In addition to the annual review attended by all ATS participants on October 16-18,1995 Solar and DOE representatives have conducted quarterly reviews. The first formal review was held February 7-8, 1996. Solar presented the ATS-S concept for DOE's concurrence, which was given contingent upon several follow up items. These were satisfactorily addressed at the subsequent review held May 14-15, 1996. Progress 
on the numerous technology development programs as well as on the S development were reviewed in detail. The $\mathrm{L}$ engine concept was also discussed and DOE input obtained. The following review, held July 31, 1996 was limited to a half day executive level.

In addition to the formal reviews, Solar has maintained close contact with DOE's COR and program office. Solar's ATS Director as well as various other key personnel have met on several occasions with DOE representatives to discuss current issues. Frequent telephone contacts are also maintained to ensure that DOE is consistently apprised of developments and has the ability to provide timely input.

Outside Funding for ATS Related Activities: Solar has endeavored to further the objectives of the ATS program by seeking other funding for activities falling outside of the cooperative agreement scope of work but which are directly related thereto.

In October, 1995 Solar submitted a proposal for California State matching funds under the Defense Conversion Matching Program. The proposal sought funding from both the California Energy Commission (CEC) and the California Trade \& Commerce Agency, Office of Strategic Technology (OST) to assist in the funding of marketing and manufacturing readiness tasks that were removed from the scope of work during negotiation of the DOE cooperative agreement. Solar was notified in December that its application had been approved but that the amount of the grant would need to be negotiated based upon the agencies' available funds.

The specific scope of work and contract terms for a $\$ 250,000$ grant from OST was negotiated over a several month period with final signatures being obtained in September, 1996. The bulk of the budget will be used to further Solar's analysis and selection of business processes and information systems consistent with Manufacturing Resource Planning (MRP II) that will enable Solar's facilities to handle the increased production volumes expected as the result of the commercialization of Solar's ATS products. Additional funds will support Solar's market readiness efforts.

Although CEC has indicated that some $\$ 25,000$ will be available to each of the applicants whose projects were approved, no substantial progress has been made towards finalizing a grant from that agency.

Solar also submitted a proposal in March to the Gas Research Institute to fund activities principally related to Solar's low emissions combustion efforts. The tasks proposed include additional testing of both ultra-lean premix and catalytic combustion, including testing of variable geometry injectors and closed loop controls. The proposed work would also extend ceramic combustion testing planned under the CSGT program to provide an additional 4,000 hours.

Solar responded in September, 1996 to several questions received from GRI and is currently awaiting notification from GRI regarding an award. 